\title{
Morphodynamic modelling of beach cusp formation: the role of wave forcing and sediment composition
}

\author{
Christopher J. Daly ${ }^{\mathrm{a}, \mathrm{b}, *}$, France Floc'h ${ }^{\mathrm{b}}$, Luis P.M. Almeida ${ }^{\mathrm{c}}$, Rafael \\ Almar $^{\mathrm{a}}$, Marion Jaud ${ }^{\mathrm{b}}$ \\ ${ }^{a}$ LEGOS, IRD, 31400 Toulouse, France \\ ${ }^{b}$ University of Brest, CNRS, IUEM, UMR 6538 Géosciences Océan, 29290 Plouzané, \\ France \\ ${ }^{c}$ Universidade Federal do Rio Grande, Rio Grande do Sul, Brazil
}

\begin{abstract}
A field of beach cusps formed during a field experiment at Nha Trang Beach, Vietnam, under accretive conditions. The measured data was used to set-up morphodynamic simulations in XBeach, which was able to simulate cusp formation from an initially long-shore uniform beach profile. Several types of simulations were run in order to observe the resulting variation in mean cusp dimensions (length, depth and height), swash flow patterns, and sediment sorting. Both time-constant (JONSWAP) and time-varying (measured) wave forcing conditions were superimposed on the measured tide. In the former, four wave parameters were varied (wave height, period, direction, and spreading), while in the latter, the median sediment size and sediment composition were varied. The wave period was found to primarily influence long-shore length scales, the wave height cross-shore length scales, and obliquely incident waves enhance all these dimensions particularly under narrow-banded conditions. Cusps are not prominent if the wave energy is too low to effect
\end{abstract}

\footnotetext{
${ }^{*}$ Corresponding Author: christopher.daly@legos.obs-mip.fr
} 
significant onshore transport, if the wave angle of incidence and spreading are too large (effectively smoothing out swash perturbations), or if the sediment is too fine in relation to the wave conditions (dissipative beaches or highly erosive wave conditions). Coarse sediment generally tends to be located on cusp horns above the waterline, but is otherwise variable depending on cross-shore location and tide levels. As the XBeach model results show large agreement with well-established norms, it may therefore be used to more rigorously study processes that help to initiate cusps in future work. Keywords: Beach cusps, Onshore sediment transport, Pattern formation, Wave forcing, Sediment sorting

\section{1. Introduction}

2 Rhythmic cuspate features are commonly observed on sandy beaches with 3 wavelengths up to $\sim 1 \mathrm{~km}$. Of these, those with long-shore wavelengths (spac4 ing) up to $\sim 50 \mathrm{~m}$ are usually considered to be formed under swash-dominant 5 processes. Numerous field studies have repeatedly shown that beach cusps 6 generally form during calm, narrow-banded, shore-normal wave conditions 7 which promote accretion (Holland, 1998; Almar et al., 2008; Vousdoukas, 8 2012; O'Dea and Brodie, 2019). Cusps also form (less frequently) under endynamic, featuring long-shore migration in which new cusp fields are generated over pre-existing formations (Masselink et al., 1997; Masselink and Pattiaratchi, 1998b; van Gaalen et al., 2011). The presence of cusps depends on local characteristics such as sediment size, beach slope and wave energy (van Gaalen et al., 2011), with cusps being more prevalent on steep, coarse 
grained, reflective beaches. Cusps are frequently characterised by their spacing, which is thought to be determined by the wavelength of edge waves (Guza and Inman, 1975) or a function of the swash excursion (Coco et al., 2001; Sunamura, 2004).

Cusps are often thought to develop via two primary mechanisms: 1) wave height patterns caused by edge waves in the long-shore dimension (Inman and Guza, 1982), or 2) from self-organisation which allows small bathymetric perturbations to grow through positive morphodynamic feedback mechanisms (Werner and Fink, 1993; Coco et al., 1999). Whether or not edge waves, self organisation, or a combination of both theories are responsible for beach cusp formation remains an open question (Holland and Holman, 1996; O'Dea and Brodie, 2019). Recent numerical simulations of nearshore flow patterns suggest that wave reflection over steep beaches can also be a mechanism for beach cusp formation (Almar et al., 2018). While much research, based on these pioneering works, has been focused on the question of how cusps are initiated, it is also important to understand how they evolve once formed under varying wave conditions and beach types (Holland, 1998; van Gaalen et al., 2011). Furthermore, while most of what is known about cusp development is based on field observations, numerical simulations have provided valuable insight into how cusps are formed (Werner and Fink, 1993; Coco et al., 2000), what processes are important for their development (Dodd et al., 2008), how their geometry affects swash flow patterns (Masselink et al., 1997), and how surf zone circulation affects cusp development (Garnier et al., 2010). Numerical simulations may therefore be used to glean knowledge on how cusps respond to changes in wave forcing and sediment composition, and to predict 
cusp morphology for specific locations.

Numerical simulations of cusp development often require specialized models capable of resolving swash dynamics and processes such as short wave runup, swash sediment transport, and groundwater infiltration and exfiltration (Coco et al., 2000, 2003; Dodd et al., 2008). It is also important to consider other processes such as sediment exchange between the swash and surf zone, wave-wave (bore) interactions and turbulence, and infragravity wave runup (Bakhtyar et al., 2009). Coco et al. (2000) and Dodd et al. (2008) used a process-based modelling approach to allow cusps to form from an initially long-shore uniform beach profile, in which sediment was reworked in the swash. As these simulations were initiated at the base of the swash, surf zone processes were not included. On the other hand, Garnier et al. (2010) excludes swash zone processes from their simulations, which showed that inner surf zone processes may enhance cusp development higher up on the beachface. Using established morphodynamic nearshore models, such as XBeach (Roelvink et al., 2009), one can simulate the entire range from surf to swash including processes important in the development of cusps.

The Kingsday version of XBeach (Roelvink et al., 2015) includes a waveresolving (non-hydrostatic) model, similar to a one-layer implementation of SWASH (Zijlema et al., 2011), and an underlying surfbeat model which allows both short and infragravity waves to be resolved in the swash. Several studies have shown the applicability of the SWASH and XBeach models to simulate wave runup, infragravity motions, swash hydrodynamics and nearshore circulation (de Bakker et al., 2014; Lashley et al., 2018; Almar et al., 2018; Roelvink et al., 2018). While the coupling of the sediment transport module 
with the non-hydrostatic wave solver is still under development, it has been used experimentally in Daly et al. (2017) and Ruffini et al. (2020). In particular, Daly et al. (2017) showed that it is possible to simulate beach accretion and berm formation in XBeach, a key process in the development of cusps. Here, we use the XBeach model to expand the work of Daly et al. (2017) from a 1D to a 2D domain in order to simulate beach cusp formation and evolution under varying wave forcing conditions and sediment composition. The model is benchmarked using data observed during a field campaign at Nha Trang Beach, Vietnam, in November 2015, during which beach cusps formed quickly during an accretionary stage lasting for a few days. We aim to evaluate the performance of the model by comparing predicted length scales, sediment sorting, and swash circulation patterns to what is expected based on observations at Nha Trang Beach and that presented in the literature. Based on the evaluation of the model performance, more detailed investigation into key processes that influence cusp initiation may be carried out in future work.

\section{Methods}

\subsection{Location and Measured Data}

An 8-day field experiment was performed at Nha Trang beach, Vietnam, from 27 November to 4 December 2015 (12 $15.17^{\prime} \mathrm{N}, 109^{\circ} 11.81^{\prime}$ E, Fig. 1). A $1200 \mathrm{kHz}$ acoustic Doppler current profiler (ADCP) placed offshore at $15 \mathrm{~m}$ depth measured significant wave heights varying between 0.6 and $1.5 \mathrm{~m}$, and mean wave periods varying between 7 and $12 \mathrm{~s}$ (Fig. 2a). Wave transformation along an instrumented cross-shore transect in the surf and swash zone were measured using four pressure transducers. A $25 \mathrm{~Hz}$ SICK 


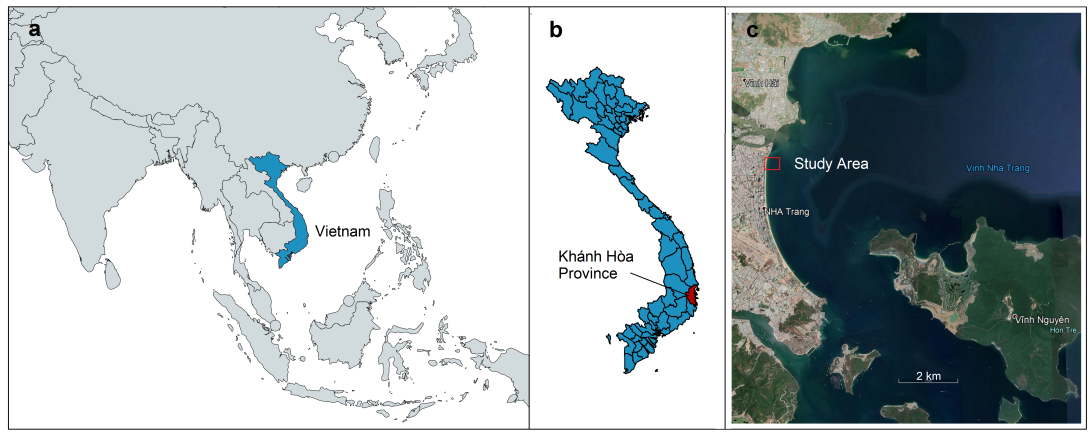

Figure 1: Location of the Nha Trang beach study site (red box in panel c), in the Khánh Hòa Province (red area in panel b), of Vietnam, southeast Asia (blue area in panel a).

LMS511 2D laser scanner was used to measure surface elevation (both of the bed and water) in the swash along the same transect, from which the swash excursion, swash height and beach slope is determined (Fig. 2c-d). The beach is composed of coarse grained sediment (median grain size, $D_{50}$ $=0.5 \mathrm{~mm}$ ) and is located in a diurnal, micro-tidal environment (tide range $=1.6 \mathrm{~m})$. As a result, the beach has a fairly steep (1:8) swash slope and a narrow low tide terrace. Beach topography data was measured using highresolution drone photogrammetry (output resolution of data points being $2.85 \mathrm{~cm})$ and closely spaced $(\sim 10 \mathrm{~m})$ RTK-GPS transects over a $1 \mathrm{~km}$ length of beach, centered on the instrumented cross-shore transect. The surveys were carried out daily and captured the rapid formation of accretionary beach cusps between 28 November and 1 December (Fig. 3). Based on these measurements, the cusps had a mean spacing of approximately $28 \mathrm{~m}$. Further details of the setup of the field experiment are presented in Almeida et al. (2020) and Daly et al. (2017). 

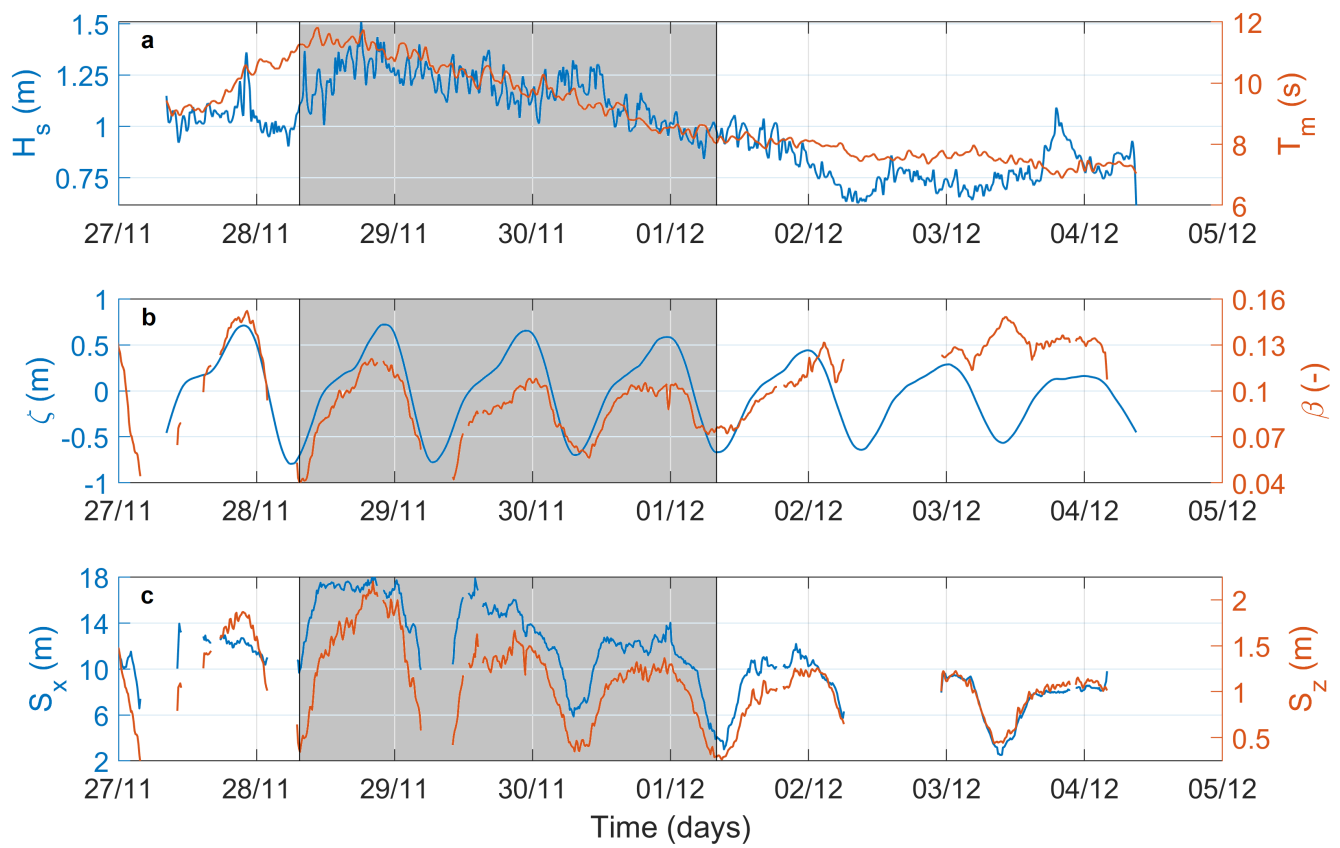

Figure 2: Wave conditions measured at the offshore ADCP and swash geometry measured with LIDAR at Nha Trang during the 2015 field experiment. (Panel a) significant wave height, $H_{s}$, and mean wave period, $T_{m}$. (Panel b) tide elevation, $\zeta$, and beach slope, $\beta$. (Panel c) swash excursion, $S_{x}$, and swash height, $S_{z}$. The three-day simulation period for Series C is highlighted in grey.

\subsection{Numerical Model}

\subsubsection{Model Description}

The Kingsday version of XBeach (cf. XBeach user manual, (Roelvink et al., 2015)) is used here with the non-hydrostatic wave solver (fully waveresolving) enabled, rather than the default surf-beat mode (wave-groupresolving). The non-hydrostatic mode gives a better representation of waves in the swash zone by combining both short and infragravity parts of the wave spectrum, albeit at the expense of having to use a much more highly resolved 

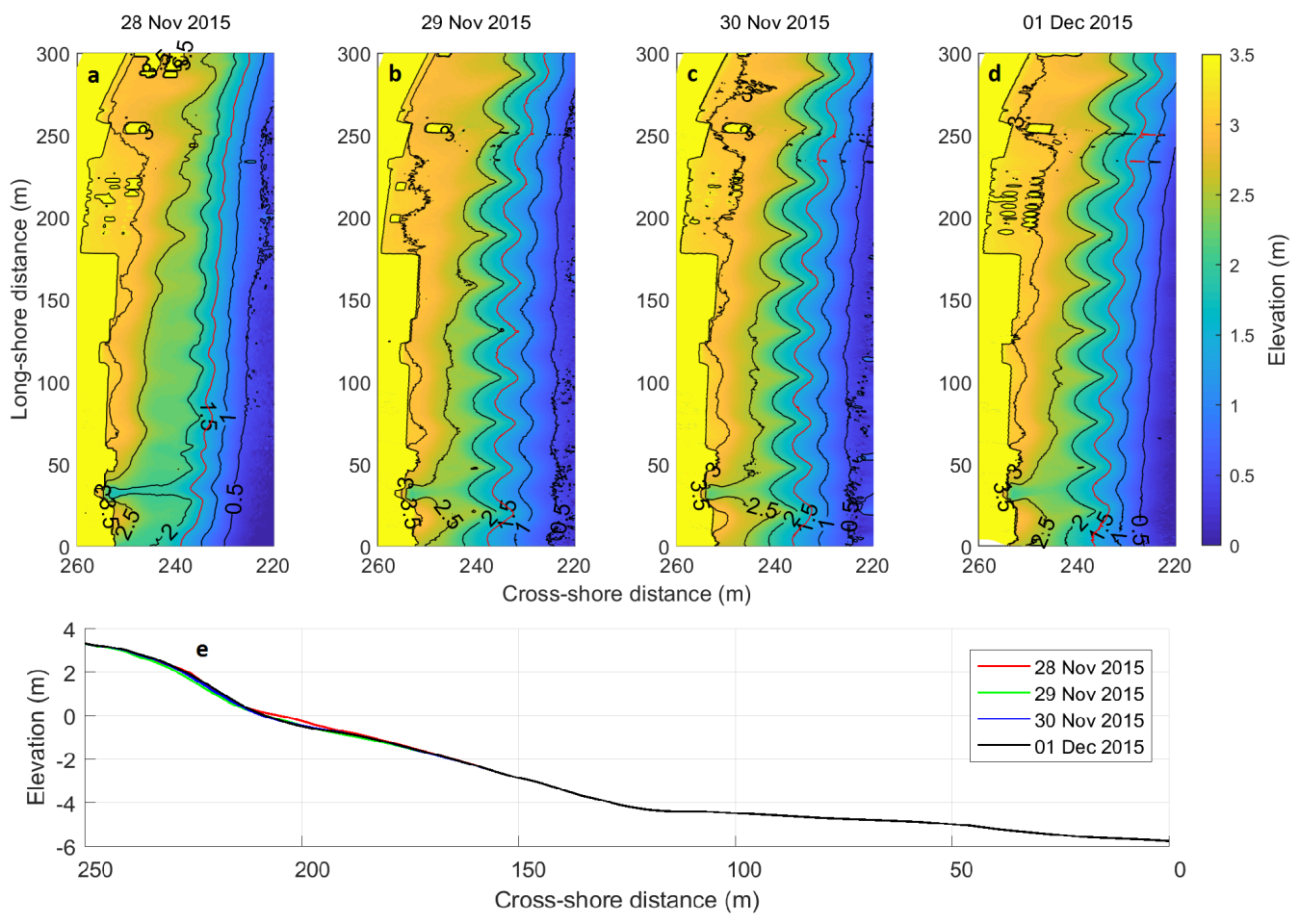

Figure 3: (Panels a-d) Measured elevations at Nha Trang during the field experiment from drone photogrammetry. Changes in morphology show the emergence of beach cusps over 3 days from 28 November (top left) to 1 December (top right), 2015. (Panel e) Long-shore-averaged cross-shore profile of the measured bathymetry.

computational grid. In non-hydrostatic mode, short-wave non-linearity is implicitly accounted for in the flow velocity at the bed, without the need for corrections based on estimates of asymmetry and skewness (e.g. Ruessink et al. (2012)). Sediment transport is computed based on mean flow conditions averaged over the wave period using advection-diffusion equations, where the Eulerian flow velocity is applied to the bed and suspended load transport formulations of Soulsby (1997), van Rijn (2007a) and van Rijn (2007b). Mean cross-shore flow (and thus, bed-load transport) tends to be negative (offshore- 
directed), driven by undertow (van der Werf et al., 2017). In nature this is can be effectively counter-balanced by non-linear wave-induced accelerations which promote net onshore transport, resulting in accretion (Elgar et al., 2001). Such intra-wave accelerations are not yet accounted for in XBeach non-hydrostatic mode as sediment transport calculations are wave-averaged, resulting in a tendency for the model to over-predict erosion. However, Daly et al. (2017) produced simulations of Nha Trang which allowed accretion of the beach. This rather unexpected result was found by using a combination of parameter settings which essentially modified the bed load transport direction in shallow water such that it is constantly positive (onshore-directed). Suspended load transport, however, is not affected, and can be both positive or negative. Therefore, although XBeach may be run with default parameter settings, some modifications are required for simulating swash morphodynamics, discussed following.

\subsubsection{Modified Parameter Settings and Prior Validation}

Identical parameter settings are used in the current suite of simulations as presented in Daly et al. (2017), shown in Table 1 below. Four groups of model parameters are changed from their default setting, relating to 1) bed friction (bedfriction and bedfriccoef), 2) bed slope effects (facsl and bdslpeffdir), 3) hindered erosion (dilatancy), and 4) groundwater flow (gwflow, gw0, $k x / k y / k z$ and gwhorinfil). A detailed description of the role each group of parameters play in achieving onshore transport is given in Daly et al. (2017), and mentioned briefly here. 1) The Manning bed friction model is used as it assigns higher friction values to shallow depths than Chézy (default model), thereby slightly damping flow velocities and allowing increased 
sediment settling and berm formation in the upper swash. 2) The parameters controlling bed slope effects modify the direction and magnitude of bed load transport based on the bed slope (cf. Walstra et al. (2007)) using the model of Talmon et al. (1995). 3) Dilatancy effects hinder erosion under high swash flows as under-pressure in the bed reduces water inflow, making it more difficult for sediment to become entrained. Dilatancy is accounted for by limiting the critical Shields number (cf. van Rhee (2010)). Finally, 4) the groundwater flow module allows water infiltration (exfiltration) into (from) the bed. Infiltration in the upper swash allows sediment deposits to build up and form berms, and is therefore a critical process in simulating swash morphodynamics. Groundwater is modelled using Darcy flow equations (cf. McCall et al. (2012)), and depends on the permeability of the sediment.

\begin{tabular}{lll}
\hline Keyword & Function & Value \\
\hline bedfriction & Bed friction formulation & Manning \\
bedfriccoef & Bed friction coefficient & 0.02 \\
facsl & Bed slope effect factor & 0.15 \\
bdslpeffdir & Modify sediment transport direction & Talmon \\
dilatancy & Turn on/off dilatancy & 1 (on) \\
gwflow & Turn on/off groundwater flow & 1 (on) \\
gw0 & Groundwater level & $0.28 \mathrm{~m}$ \\
kx/ky/kz & Darcy flow permeability coefficient & 0.001 \\
gwhorinfil & Turn on/off horizontal infiltration & 1 (on) \\
\hline
\end{tabular}

Table 1: XBeach model settings changed from default

The modified model settings in Table 1 have been validated for the location at Nha Trang Beach in Daly et al. (2017). Their simulations were done over the 1-dimensional long-shore-averaged beach profile starting on 27 
November 2015 and run for 6 days. Comparisons between the model output and measured $H_{s}$ data at several locations in the inner surf and swash zone had an average root-mean-square error of $0.15 \mathrm{~m}$ and correlation coefficient of 0.94. Furthermore, comparison between the simulated and measured mean cross-shore profile showed a root-mean-square error or $0.11 \mathrm{~m}$. Those results showed that the model reproduces wave transformation up to the swash zone quite well, and also reasonably predicts berm formation on the upper beach. Further validation of the model is therefore not necessary here, as the focus of the study now shifts to assessing the effect varying wave conditions and sediment composition has on cusp formation.

\subsection{Numerical Simulations}

\subsubsection{Model Grid and Timing}

The mean cross-shore profile of the study area on 28 November is used to create a long-shore uniform initial bathymetry for the model (Fig. 3e). When using the non-hydrostatic wave mode in XBeach, a detailed computational grid is required. As such, a grid spacing of 0.75 and $1.5 \mathrm{~m}$ in the cross-shore and long-shore directions are used in the surf and swash zone (area above $2 \mathrm{~m}$ depth), respectively. Initial tests with a finer cross-shore grid spacing of $0.5 \mathrm{~m}$ did not significantly change the final result. At the offshore model boundary, the water depth is $6 \mathrm{~m}$ and a maximum cross-shore spacing of $2 \mathrm{~m}$ is used, which gradually decreases toward the resolution used in the surf and swash zone. The grid spacing used allows waves down to 3 s to be clearly resolved across the entire domain with a minimum 8 points per wavelength (and 16 points per wavelength for periods over $7 \mathrm{~s}$ ). The high resolution grid in the surf and swash zone also allows beach cusps with wavelengths upwards 
of $12 \mathrm{~m}$ to be adequately resolved.

All simulations are run for a period of three days, representing the period during which cusps formed during the field experiment between 28 November and 1 December, 2015, (Fig. 3). The three day period is expected to be sufficient time for cusps to fully form in the model, given that it took only one day for them to emerge during the field experiment. As the computational effort for each simulation is expensive, a modest morphological acceleration factor (morfac) of 6 is used to speed up the simulations. Comparable results were obtained for test simulations run with morfac turned on and off. The model determines the time step based on a prescribed maximum Courant number ( 0.7 by default).

The output model domain is limited to a dedicated $240 \times 250 \mathrm{~m}$ area in the long-shore $(y)$ and cross-shore $(x)$ dimensions, respectively. This area is sufficient to observe the development of cusps with long-shore wavelengths up to $60 \mathrm{~m}$ (minimum 4 wavelengths within the domain). A buffer area is added at either end of the output model domain to account for boundary effects, especially in cases where waves approach the beach at an oblique angle and create shadow zones. This area is removed during the post-processing of the results. In order to limit the size of the output files, time-averaged and instantaneous global variables (i.e. 2-dimensional) are saved every 10 minutes (e.g. bed levels, surface elevation, velocity and bed composition). A more highly resolved time series is saved every $0.5 \mathrm{~s}$ for output variables at several points along the central cross-shore transect (at $y=120 \mathrm{~m}$ ). 


\subsubsection{Wave Conditions and Sediment Composition}

Simulations are run using either time-constant or time-varying (measured) wave forcing conditions. All simulations are run with the same timevarying (measured) diurnal tidal water levels imposed on the model boundary. For simulations with time-constant wave forcing, a random time-series of surface waves are generated using a JONSWAP spectrum defined by four parameters: the significant wave height $\left(H_{s}\right)$, mean wave period $\left(T_{m}\right)$, directional spreading $(\sigma)$, and angle of incidence $(\theta)$. The values of $H_{s}$ and $T_{m}$ fall within close range of the measured conditions during the field experiment (cf. Fig. 2). A base case simulation uses $\left[H_{s}, T_{m}, \sigma, \theta\right]=[1.3 \mathrm{~m}, 10 \mathrm{~s}, 0$ ${ }^{\circ}, 0^{\circ}$. From this simulation, each parameter is varied with values shown in Table 2 below. The 2-dimensional $H_{s}-T_{m}$ parameter space is completely filled with the exception that at $H_{s}=0.7 \mathrm{~m}$ there is no simulation at $T_{m}=$ $11.4 \mathrm{~s}$, and at $H_{s}=1.7 \mathrm{~m}$ there is no simulation at $T_{m}=7.3 \mathrm{~s}$, as these wave conditions are far from those observed. The parameter space for $\sigma$ and $\theta$ is 1-dimensional. There are 14 time-constant wave simulations for the $H_{s}-T_{m}$ parameter space (Series A1 - A14, including the base case at A10), and 6 other simulations for the $\sigma$ and $\theta$ parameter space (Series B1 - B6).

\begin{tabular}{ll}
\hline Wave Parameter & Values Used \\
\hline$H_{s}(\mathrm{~m})$ & {$[0.7,1.0,1.3,1.7]$} \\
$T_{m}(\mathrm{~s})$ & {$[7.3,8.7,10.0,11.4]$} \\
$\sigma\left(^{\circ}\right)$ & {$[0,5,10,15]$} \\
$\theta\left(^{\circ}\right)$ & {$[0,5,10,15]$} \\
\hline
\end{tabular}

Table 2: Wave parameter values used to define JONSWAP boundary wave conditions Simulations using time-varying (measured) wave conditions directly use 
the time-series of wave conditions recorded by the offshore ADCP during the field campaign (cf. Fig. 2). The wave direction is, however, kept constant at $0^{\circ}$ (normally incident). The median grain size, $D_{50}$, is varied in these simulations as $[0.5,0.3,0.2,0.5 / 0.2] \mathrm{mm}$ (Series $\mathrm{C} 1-\mathrm{C} 4$, respectively). The first $(0.5 \mathrm{~mm})$ represents the native size of sediment of the beach while the other sizes are exploratory. The latter size $(0.5 / 0.2 \mathrm{~mm})$ features an evenly mixed sediment bed of coarse and fine sediment, respectively.

\subsubsection{Analysis of Results}

Contour lines are extracted from output bed level data between -1.5 and $2.5 \mathrm{~m}$ elevation at $0.1 \mathrm{~m}$ intervals. The spatial dimensions of the beach cusps produced during the simulations are determined by Fourier analysis of each contour level at each point in time, yielding the mean long-shore wavelength (or cusp spacing, $L_{y}$ ) and cross-shore depth $\left(L_{x}\right)$. Similarly, the vertical height $\left(L_{z}\right)$ of the cusps are derived from the analysis of the detrended longshore bed level at each cross-shore location. Variation of the bathymetry $\left(z_{b}\right)$ in the long-shore dimension is computed by removing the long-shore mean profile from each cross-shore transect:

$$
\widetilde{z_{b, y}}=z_{b}-\overline{z_{b, y}}
$$

Subsequently, the root-mean-square (RMS) long-shore bed level variation $(\Delta)$, which indicates the degree of vertical variability in bed levels and thus prominence of the cuspate features, is computed as:

$$
\Delta=\sqrt{\sum_{z_{b}=0.5}^{z_{b}=1.0}{\widetilde{z_{b, y}}}^{2}}
$$


Only data located between 0.5 and $1 \mathrm{~m}$ elevation are used Eq. 2, an area in which cusp features are consistently located for all simulations. Beach cusps are considered to be present if $\Delta>2 \mathrm{~cm}, L_{z}>5 \mathrm{~cm}$ and the aspect ratio $\left(A R=L_{y} / L_{x}\right)<25$. They are also considered to be prominent if $\Delta>10$ $\mathrm{cm}, L_{z}>20 \mathrm{~cm}$ and $A R<10$.

Long-shore variation (or anomaly) of the time-averaged (over a 10 minute period) significant wave height and cross-shore current $(u)$ field over the model domain $\left(\left\langle\widetilde{H_{s, y}}\right\rangle\right.$ and $\left\langle\widetilde{u_{y}}\right\rangle$, respectively) are also computed in a similar fashion as $\widetilde{z_{b, y}}$ in Eq. 1. Turbulent kinetic energy $(k)$ is computed from the time series output of cross-shore and long-shore velocity components $(u$ and $v$, respectively) along the central cross-shore transect as:

$$
k=\frac{1}{2}\left(\overline{\left(u^{\prime}\right)^{2}}+\overline{\left(v^{\prime}\right)^{2}}\right)
$$

where $u^{\prime}$ and $v^{\prime}$ are fluctuations of the velocity components after removal of the mean over a sample period of 10 minutes.

The swash excursion $\left(S_{x}\right)$ is computed along the central cross-shore swash profile (at $y=120 \mathrm{~m}$ ), where water and bed level data are stored at high frequency $(2 \mathrm{~Hz})$ and at $1 \mathrm{~m}$ intervals. $S_{x}$ is taken as the difference between the cross-shore position of the lower and upper level of the wet/dry interface (at the $2^{\text {nd }}$ and $98^{\text {th }}$ percentiles, respectively) during successive 10-minute intervals (n.b., a grid point is considered dry once $h<5 \mathrm{~cm}$ ). The swash height $\left(S_{z}\right)$ is the corresponding difference between the lower and upper elevation of the wet/dry interface during the same time interval. The swash slope $(\beta)$ is equal to $S_{z} / S_{x}$.

Finally, the surface sediment composition, $P_{D_{50}}$ is computed for case C4 
(having a mixed sediment bed) as:

$$
P_{D_{50}}=\frac{P_{c, t}-P_{c, i}}{P_{c, i}}
$$

where $P_{c}$ is the percentage of coarse sediment in the surface layer initially (subscript $i$, and where $P_{c, i}=50 \%$ ) or at any time during the simulation (subscript $t$ ). Thus, $P_{D_{50}}$ values of 1,0 and -1 indicate that the surface sediment is $100 \%$ coarse, evenly mixed (50\% coarse and 50\% fine) and $100 \%$ fine, respectively.

\section{Results}

\subsection{Predicted Length Scales}

The final bathymetries for all 24 simulations (taken at the last mid-tide level at 2.83 days) are shown in Fig. 4. The 14 simulations in Series A are shown in Fig. 4a-n, the 6 simulations in Series B are shown in Fig. 4o-t, and finally, the 4 simulations in Series $\mathrm{C}$ are shown in Fig. $4 \mathrm{u}-\mathrm{x}$. Here, it is seen that cusps clearly develop for certain cases and are subdued for others. For the cases where cusps do form, they are generally located in a narrow area between 0 and $1.5 \mathrm{~m}$ elevation on the sub-aerial beach face. Prominent cusps are obtained for cases A10-14, B1, B4 and C1.

The length scales of the cusps vary as they evolve, depending on the elevation of the tide and the movement of the swash zone up and down the beach face, as shown for the base case (A10) in Fig. 5. Cusps generally begin to appear after the first tidal cycle with low $\Delta$ values, which are then enhanced over the remaining two tidal cycles. At the end of the simulations, the level 

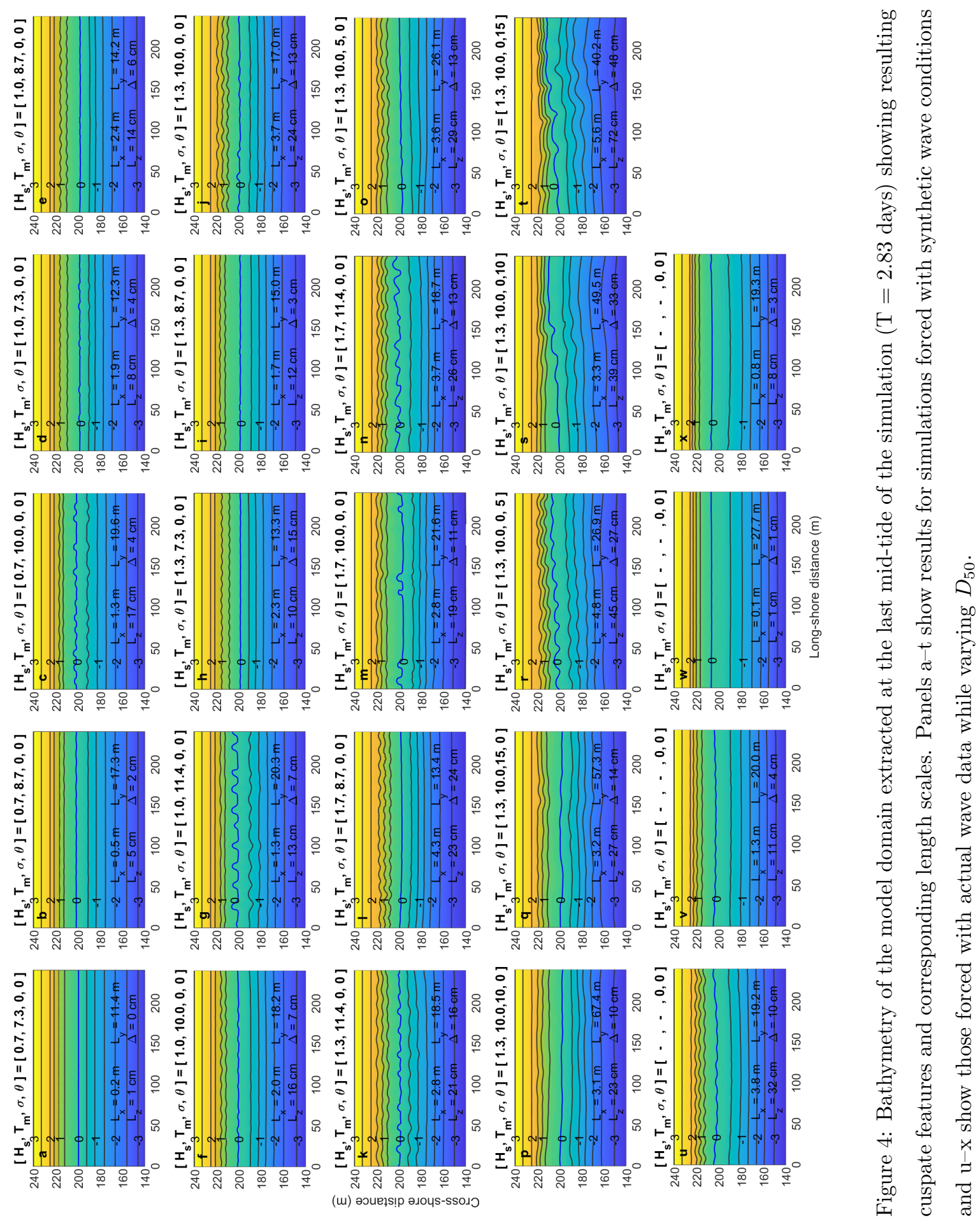
of the tide is low, leaving the upper beach exposed and morphologically inactive. It is at this moment (mid-tide occurring at 2.83 days) that final values of $L_{x}, L_{y}, L_{z}, \Delta$ and $A R$ are taken as representative of the response to the prescribed forcing conditions or sediment composition.

\subsubsection{Series $A$ : Varying $H_{s}$ and $T_{m}$}

Fig. $4 \mathrm{a}-\mathrm{n}$ shows prominent cusps develop for certain combinations of $H_{s}-T_{m}$ (generally when $H_{s}>1.3 \mathrm{~m}$ and $T_{m}>10 \mathrm{~s}$ ) and are subdued for others (generally when $H_{s}<1 \mathrm{~m}$ and $T_{m}<10 \mathrm{~s}$ ). There is one case where beach cusps do not form at all (case A1), despite accretion of the beach face. Fig. 6a-d shows the resulting length scales for the simulations in Series A. For cases where cusps are present (A2 - A14), $L_{y}$ varies between $12-22 \mathrm{~m}$. Increases in $T_{m}$ (for the same $H_{s}$ ) generally results in increased $L_{y}$ (warmer colours concentrated in top half of Fig. 6b). $L_{x}$ and $L_{z}$ increases with increasing $H_{s}$ and, to a lesser extent, with $T_{m}$ (warmer colours concentrated in the top right of Fig. $6 \mathrm{a}$ and $\mathrm{c}$ ). And finally, increased $\Delta$ values are generally associated with larger $H_{s}$ (warmer colours concentrated on right side of Fig. 6d).

\subsubsection{Series B: Varying $\sigma$ and $\theta$}

Fig. $6 \mathrm{e}-\mathrm{h}$ shows the response values of cusp length scales to changes in $\sigma$ and $\theta$. Increasing values of $\sigma$ and $\theta$ from 0 produce large increases in $L_{y}$, with values ranging between $26-67 \mathrm{~m}$. This is a significant increase in $L_{y}$ compared to the base case, where $L_{y}$ is $17 \mathrm{~m}$. This may be explained by the increased width of the swash trajectory (i.e. the path a water particle traces during swash and backwash, distinct from $S_{x}$ ) for higher values of $\sigma$ and $\theta$. 

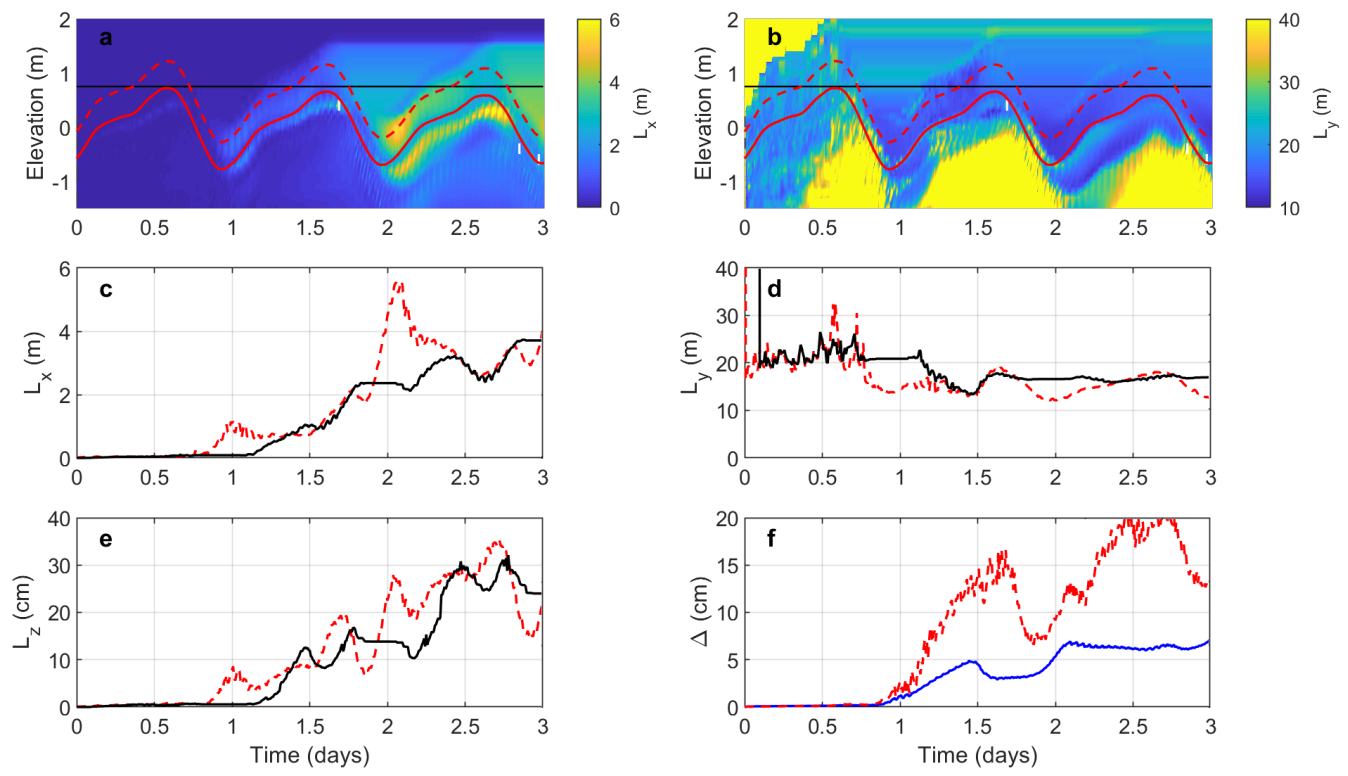

Figure 5: Evolution of beach cusp length scales for the base case simulation. (a-b) Variation of $L_{x}$ (a) and $L_{y}$ (b) as a function of time and elevation relative to MSL. The solid red line indicates the height of the tide (near the lower limit of the swash) and the dashed red line shows (approximately) the upper limit of the swash at $0.5 \mathrm{~m}$ above the tide level. The solid black line shows the maximum tide level of $0.75 \mathrm{~m}$ elevation. Changes in $L_{x}$ and $L_{y}$ occur as the swash zone moves up and down the beach face. At low tide (at time $=1,2$ and 3 days), the upper beach is dry and morphologically inactive. (c-f) Changes in $L_{x}, L_{y}, L_{z}$ and $\Delta$ as a function of time, respectively. The dashed red line and solid black lines correspond to those defined in $(\mathrm{a}-\mathrm{b})$. The solid blue line in (f) is the average $\Delta$ taken between 0.5 and $1 \mathrm{~m}$ elevation. $L_{x}, L_{z}$ and $\Delta$ remain low during the first tidal cycle as the planar beach begins to react to the imposed forcing conditions. They subsequently increase over the remaining two tidal cycles. 


\begin{tabular}{|c|c|c|c|c|c|c|c|c|c|c|}
\hline $\begin{array}{l}\text { Run } \\
\text { ID }\end{array}$ & $\begin{array}{l}H_{s} \\
(\mathbf{m})\end{array}$ & $\begin{array}{l}T_{m} \\
(\mathbf{s})\end{array}$ & $\begin{array}{l}\sigma \\
\left(^{\circ}\right) \\
\end{array}$ & $\begin{array}{l}\theta \\
\left({ }^{\circ}\right) \\
\end{array}$ & $\begin{array}{l}D_{50} \\
(\mathbf{m m})\end{array}$ & $\begin{array}{l}L_{x} \\
(\mathbf{m})\end{array}$ & $\begin{array}{l}L_{y} \\
(\mathbf{m})\end{array}$ & $\begin{array}{l}L_{z} \\
(\mathbf{c m})\end{array}$ & $\begin{array}{l}\Delta \\
(\mathbf{c m})\end{array}$ & $\begin{array}{l}A R \\
(-)\end{array}$ \\
\hline $\mathrm{A} 1$ & 0.7 & 7.3 & 0 & 0 & 0.5 & 0.2 & 11.4 & 1 & 0 & 57 \\
\hline $\mathrm{A} 2$ & 0.7 & 8.7 & 0 & 0 & 0.5 & 0.5 & 17.3 & 5 & 2 & 35 \\
\hline A 3 & 0.7 & 10.0 & 0 & 0 & 0.5 & 1.3 & 19.6 & 17 & 4 & 15 \\
\hline $\mathrm{A} 4$ & 1.0 & 7.3 & 0 & 0 & 0.5 & 1.9 & 12.3 & 8 & 4 & 6.5 \\
\hline A 5 & 1.0 & 8.7 & 0 & 0 & 0.5 & 2.4 & 14.2 & 14 & 6 & 5.9 \\
\hline $\mathrm{A} 6$ & 1.0 & 10.0 & 0 & 0 & 0.5 & 2.0 & 18.2 & 16 & 7 & 9.1 \\
\hline A7 & 1.0 & 11.4 & 0 & 0 & 0.5 & 1.3 & 20.3 & 13 & 7 & 16 \\
\hline A 8 & 1.3 & 7.3 & 0 & 0 & 0.5 & 2.3 & 13.3 & 10 & 15 & 5.8 \\
\hline A9 & 1.3 & 8.7 & 0 & 0 & 0.5 & 1.7 & 15.0 & 12 & 3 & 8.8 \\
\hline A10 & 1.3 & 10.0 & 0 & 0 & 0.5 & 3.7 & 17.0 & 24 & 13 & 4.6 \\
\hline A11 & 1.3 & 11.4 & 0 & 0 & 0.5 & 2.8 & 18.5 & 21 & 16 & 6.6 \\
\hline A12 & 1.7 & 8.7 & 0 & 0 & 0.5 & 4.3 & 13.4 & 23 & 24 & 3.1 \\
\hline A 13 & 1.7 & 10.0 & 0 & 0 & 0.5 & 2.8 & 21.6 & 19 & 11 & 7.5 \\
\hline A14 & 1.7 & 11.4 & 0 & 0 & 0.5 & 3.7 & 18.7 & 26 & 13 & 5.1 \\
\hline B1 & 1.3 & 10.0 & 5 & 0 & 0.5 & 3.6 & 26.1 & 29 & 13 & 7.3 \\
\hline B2 & 1.3 & 10.0 & 10 & 0 & 0.5 & 3.1 & 67.4 & 23 & 10 & 22 \\
\hline B3 & 1.3 & 10.0 & 15 & 0 & 0.5 & 3.2 & 57.3 & 27 & 14 & 18 \\
\hline B4 & 1.3 & 10.0 & 0 & 5 & 0.5 & 4.8 & 26.9 & 45 & 27 & 5.6 \\
\hline B5 & 1.3 & 10.0 & 0 & 10 & 0.5 & 3.3 & 49.5 & 39 & 33 & 15 \\
\hline B6 & 1.3 & 10.0 & 0 & 15 & 0.5 & 5.6 & 40.2 & 72 & 48 & 17 \\
\hline C1 & varies & varies & 0 & 0 & 0.5 & 3.8 & 19.2 & 32 & 10 & 5.1 \\
\hline $\mathrm{C} 2$ & varies & varies & 0 & 0 & 0.3 & 1.3 & 20.0 & 11 & 4 & 15 \\
\hline C3 & varies & varies & 0 & 0 & 0.2 & 0.1 & 27.7 & 1 & 1 & 277 \\
\hline $\mathrm{C} 4$ & varies & varies & 0 & 0 & $0.5 / 0.2$ & 0.8 & 19.3 & 8 & 3 & 24 \\
\hline
\end{tabular}

Table 3: Simulation Results (base case in bold)

315 It is important to also note in Fig. 4 that for cases where $\theta$ is varied, the 316 resulting cusps are saw-toothed shaped due to the asymmetry of the swash 
trajectory. This is not seen in the cases where $\sigma$ is varied, as the swash trajectory is symmetrical about the shore normal. For increased $\sigma, L_{x}$ tends to slightly decrease while $L_{z}$ and $\Delta$ remain fairly stable. For increased $\theta, L_{x}$, $L_{z}$ and $\Delta$ tend to increase.

\subsubsection{Series C: Time-varying wave conditions}

Case C1, run with measured wave data and the native sediment size of $0.5 \mathrm{~mm}$, produced prominent cusp patterns with $L_{x}$ and $L_{y}$ equal to 3.8 and $19.2 \mathrm{~m}$, respectively. Cusp patterns also emerge much earlier (after $\sim 3$ hours) than the simulations with constant wave forcing (after $\sim 18$ hours), as the wave conditions regularly changes with time. The beach cusps themselves are also more dynamic, with greater long-shore migration observed in contrast to relatively static cusps in the simulations with constant wave forcing. For the remaining cases, cusps are either weakly defined (C2 and C4) or non-existent (C3). For the latter (C3), the finer sediment size of $0.2 \mathrm{~mm}$ causes the beach to strongly erode under the same wave conditions at case C1.

When the sediment size is decreased to 0.3 and $0.2 \mathrm{~mm}$ (cases C2 and C3, respectively), the upper beach no longer accretes, but is rather eroded to form a low tide terrace (wide shallow area around MSL in Figure $4 \mathrm{v}-\mathrm{x}$ ). Cuspate features can still be discerned for in the pattern of erosion for the case C2, however the beach is featureless for case C3 as the wave conditions are highly erosive for the fine sediment, resulting in a dissipative beach profile. 

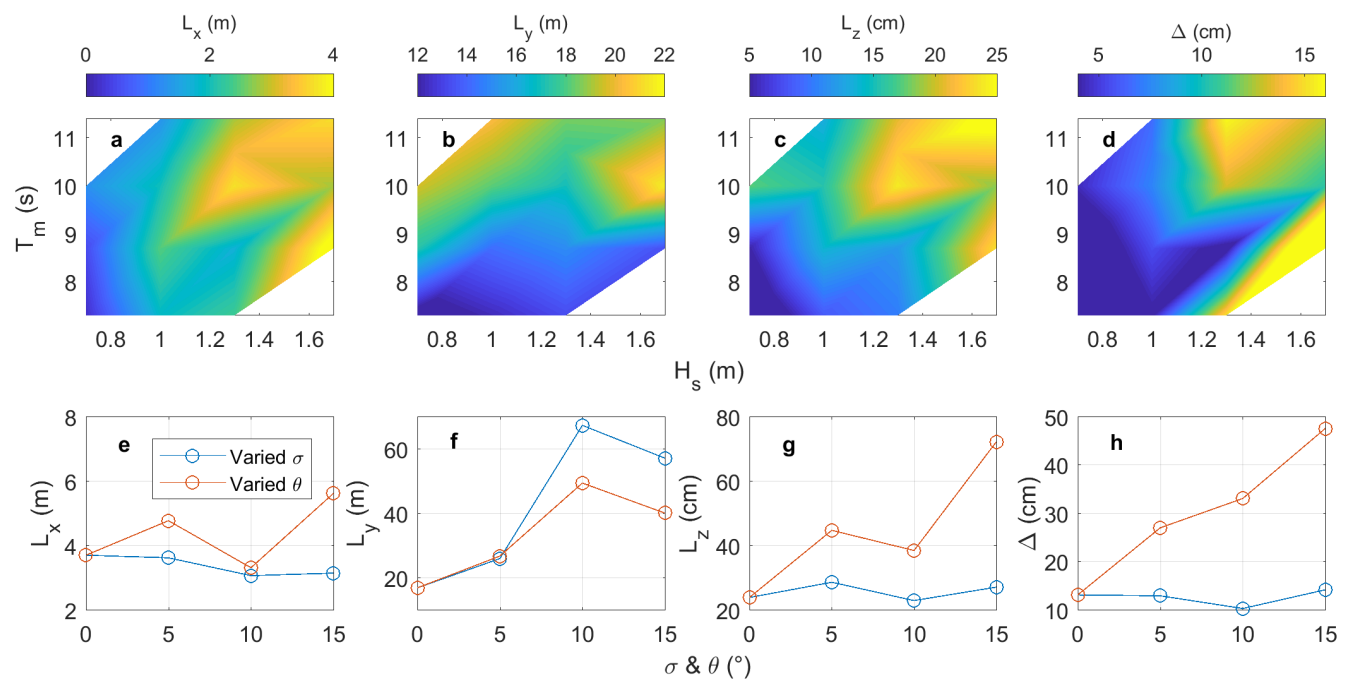

Figure 6: Resulting length scales of $L_{x}, L_{y}, L_{z}$ and $\Delta$ for different combinations of wave conditions in the $H_{s}-T_{m}$ parameter space (panels a-d) and, separately, in the $\sigma$ and $\theta$ parameter space (panels e-h). Note that the legend in panel (e) also applies to panels (f-h).

\subsection{Temporal Evolution and Swash Dynamics}

\subsubsection{Temporal development of cusps}

Fig. 7 shows the temporal evolution of cuspate morphology for the base case simulation (A10), which is fairly representative for all the other cases considered. During the initial rising tide, small alternating perturbations in the wave and current field are observed. The perturbations are, however, too small cause any significant variation in $\left\langle\widetilde{H_{s, y}}\right\rangle$ or $\left\langle\widetilde{u_{y}}\right\rangle$, therefore the bathymetry is slow to respond. Nonetheless, during this initial period, sediment is slowly moved onshore, just below the tide level (Fig. 7f). This subaqueous mass of accreted sediment becomes exposed when the tide turns after the first high tide. It is reworked and sediment is freshly deposited at 


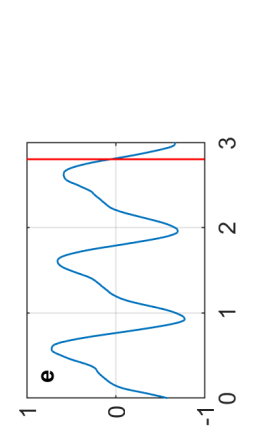

(ui) ${ }^{0} q z-{ }^{q} z$

(ui) $\stackrel{f^{i} q_{z}}{\sim}$

(ui) $\left\langle{ }^{n ! s} H\right\rangle$
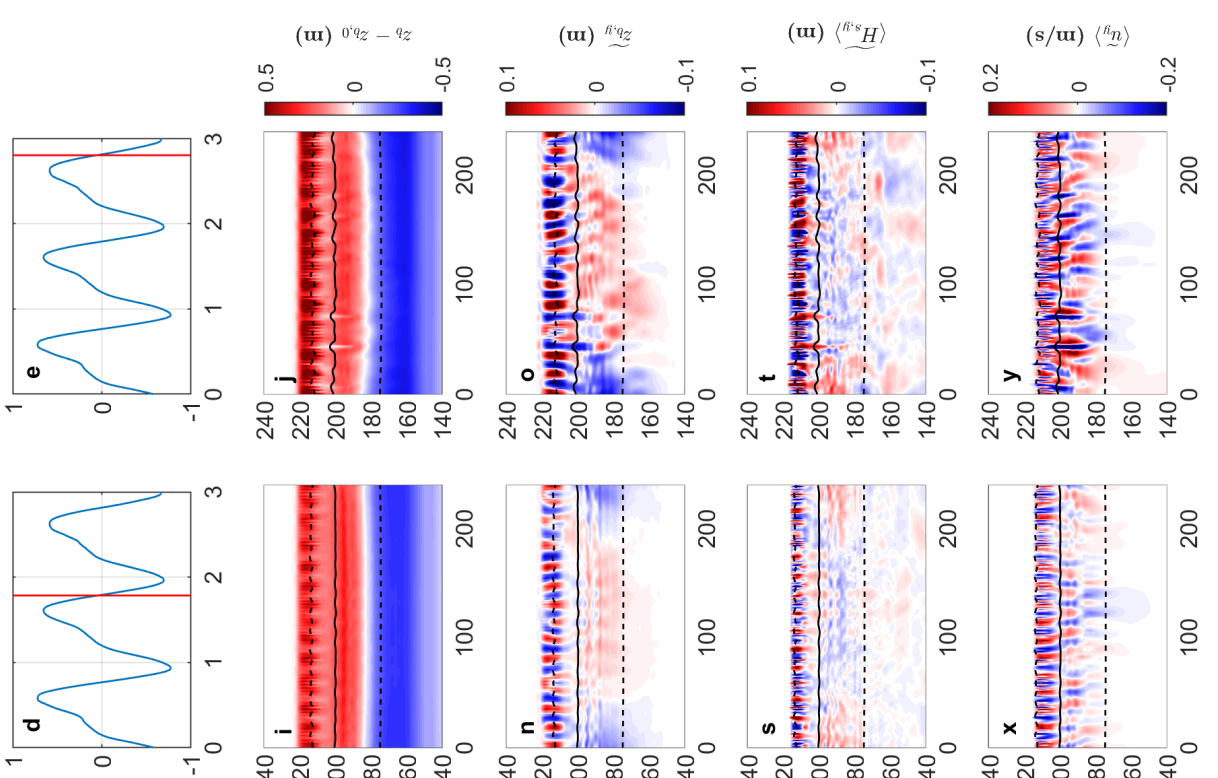

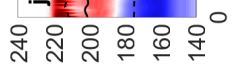
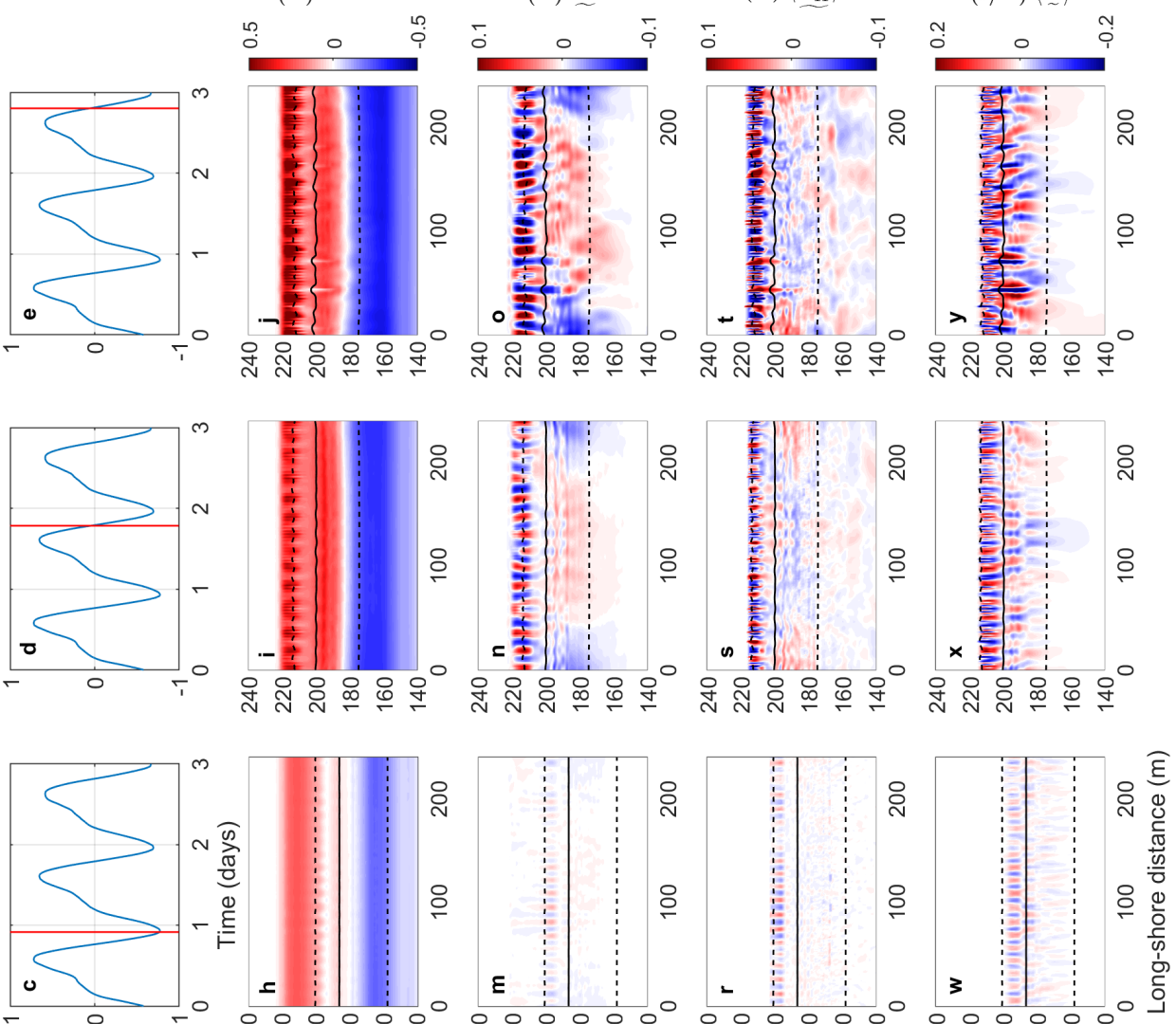

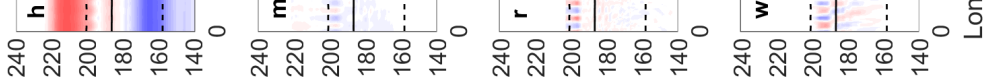
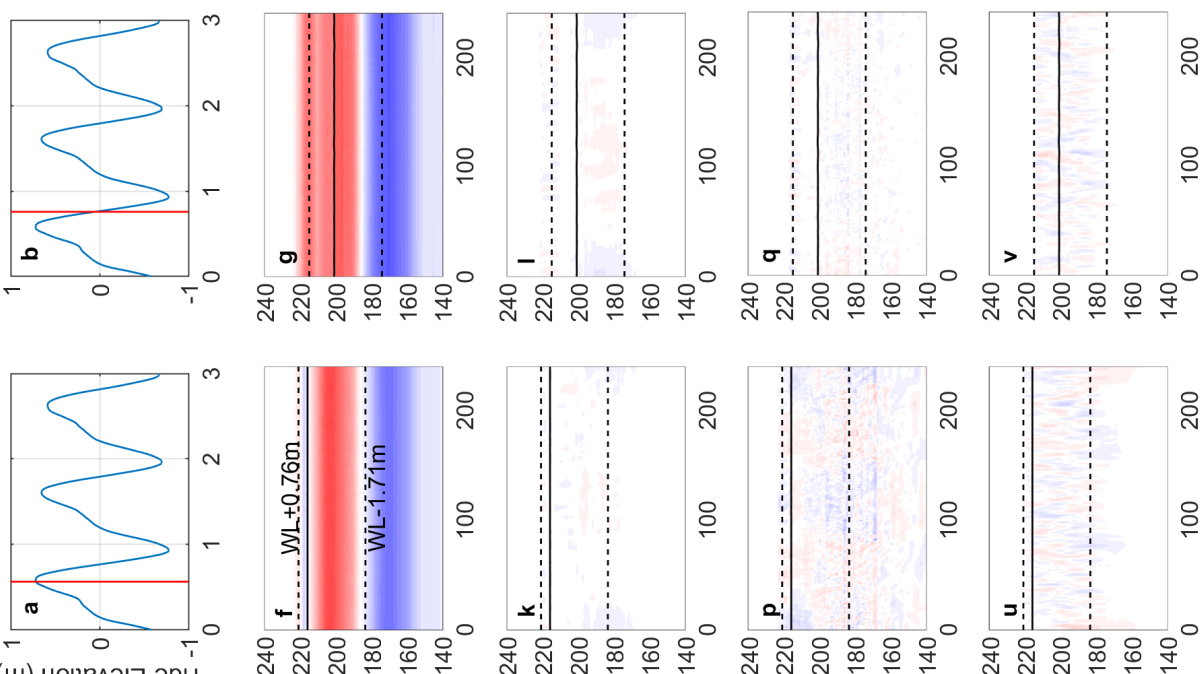

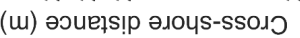

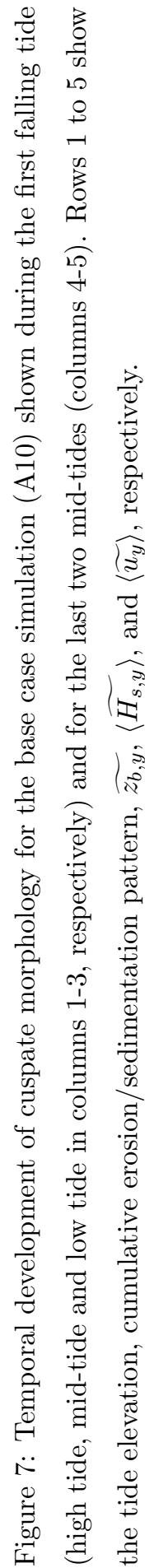


the top of the swash as the water level recedes, creating a berm (Fig. $7 \mathrm{~g}$ ). This trail of sediment is slowly sculpted into small cuspate features as sediment deposition becomes irregular long-shore. By the start of the second tidal cycle, these remnant cuspate perturbations, $\widetilde{z_{b, y}}$, begin to amplify the wave height pattern to a sufficient degree to cause notable variations in $\left\langle\widetilde{H_{s, y}}\right\rangle$ and $\left\langle\widetilde{u_{y}}\right\rangle$, which further enhances $\widetilde{z_{b, y}}$ through positive feedback. Over time, these feedbacks allow the cusp dimensions to steadily increase over time, particularly $L_{x}, L_{z}$ and $\Delta$ (as shown in Fig. 5).

For all simulations, the $\left\langle\widetilde{H_{s, y}}\right\rangle$ pattern is consistently negatively correlated with $\widetilde{z_{b, y}}(-0.33>r>-0.64$, averaged over last tidal cycle), with both patterns developing simultaneously. This indicates that wave heights are higher on the cusp horns and smaller in the troughs. Simulations in which the cusp field does not clearly materialize are those in which accretion is not particularly strong during the initial (and subsequent) tidal cycles, especially in the upper part of the beach. The cusp field also does not fully develop in simulations where the pattern of $\left\langle\widetilde{H_{s, y}}\right\rangle$ or $\left\langle\widetilde{u_{y}}\right\rangle$ is not strongly perturbed.

\subsubsection{TKE and swash flow patterns}

The variation of $k$ along the central cross-shore transect allows us to see areas where wave-breaking-induced turbulence is strongest. The left panels in Fig. 8 show that $k$ is maximum in the inner surf zone during the falling tide, maximum in the swash around high tide. Greater levels of swash turbulence around high tide (where cusps are to be found) is observed for increasing $H_{s}, \sigma$ and $\theta$. Swash flow patterns are generally found to be horn-divergent, with flow converging in the trough of the cusp with strong return currents (Fig. 8b and d). Flow patterns are elongated in swash for slightly increased 
$\theta$ (case B4, Fig. 8f). The increased turbulence for small increases of $\sigma$ and $\theta$ beyond normal potentially amplifies cusp dimensions, but may prove to be too dynamic for larger values above normal. Fig. $8 \mathrm{~g}$ and $\mathrm{h}$ show, for case B3, $k$ values are consistently high in the surf and for longer periods in the swash around high tide compared to the base case. The resulting mean flow pattern lacks the rhythmicity observed in the base case, with more uniform cross-shore flow.

\subsubsection{Swash Excursion, Height and Slope}

Fig. 9 shows $S_{x}, S_{z}$ and $\beta$ for the base case simulation, which has similar results as most other cases. As seen in Fig. 9b, $\beta$ and tide elevation are positively correlated, varying at the same timescale (i.e., the beach is steeper around high tide and more gently sloping around low tide). $S_{x}$ is consistently negatively correlated with the swash slope and tide elevation above MSL (i.e., $S_{x}$ is smallest around high tide, where the beach slope is steepest). In some cases, $S_{x}$ is maximum at low tide while in others $S_{x}$ is maximum just below mid-tide and subsequently decreases towards low tide (Fig. 9c). The latter is due to a berm forming at the low tide level that increases $\beta$ around that section of the beach profile. $S_{x}$ and $S_{z}$ increases, as expected, with increased $H_{s}$. For the base case (A10), the swash excursion generally ranges between 6 $16 \mathrm{~m}$; and for case $\mathrm{C} 1$ it ranges between $8-20 \mathrm{~m}$. At the end of the simulation, $S_{x}$ measures $9.5 \mathrm{~m}$ for case A10 and $13.9 \mathrm{~m}$ for case C1.

\subsection{Surface Sediment Composition}

The final simulation (case C4) shows the effect of varying the sediment composition by including two classes of sediment (fine and coarse) in the 

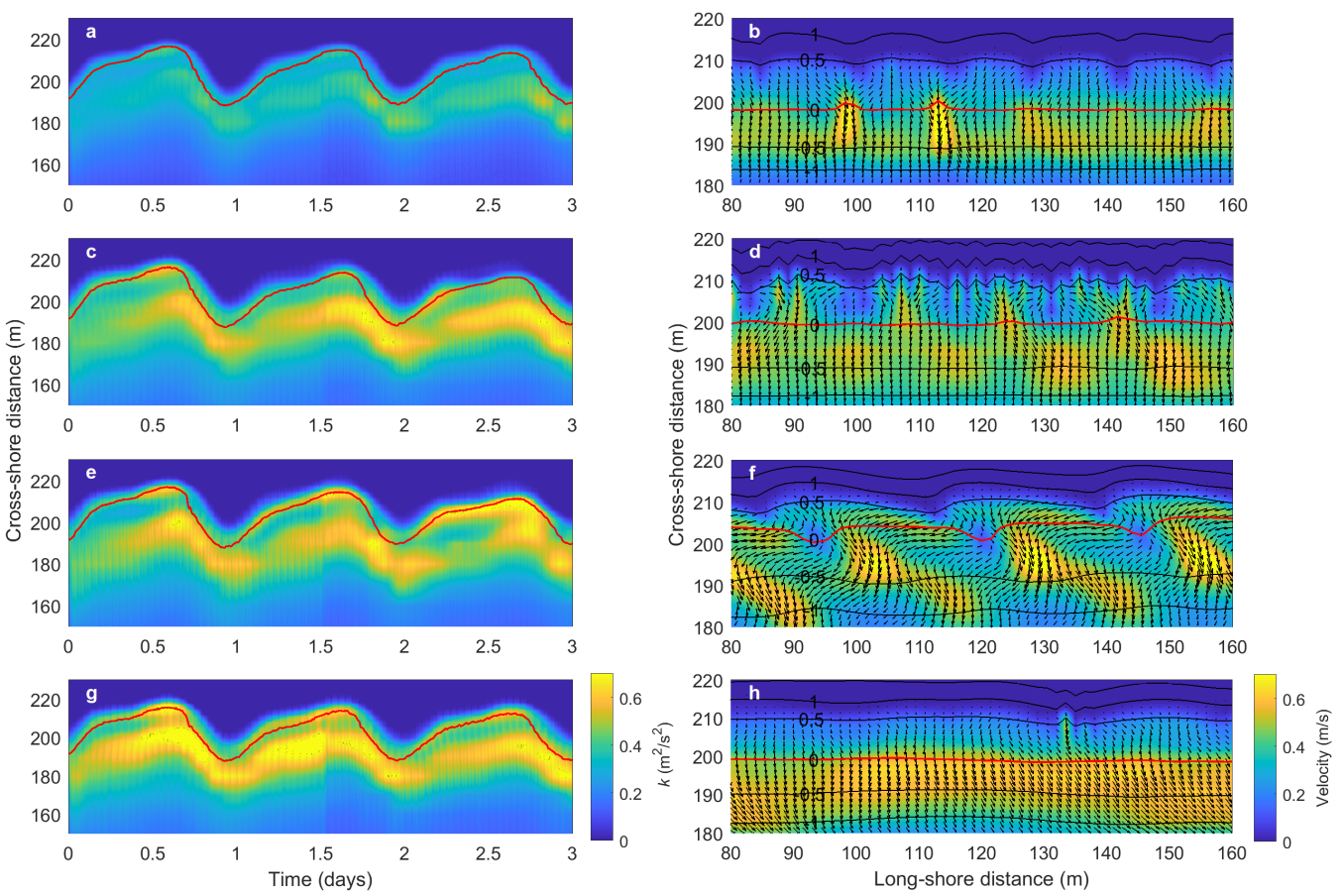

Figure 8: (Left panels) Temporal variation of turbulent kinetic energy $(k)$ along the central cross-shore transect $(y=120 \mathrm{~m})$ for cases A5, A10 (base case), B4 and B3 (panels a, c, e, and g, respectively). Red line indicates tide level. (Right panels) Spatial variation of the mean swash velocity field taken around the last mid-tide level ( $\mathrm{T}=2.83$ days) for cases A5, A10 (base case), B4 and B3 (panels b, d, f, and h, respectively). Red line indicates shoreline ( $0 \mathrm{~m}$ contour level), and black lines show contour levels above and below spaced $0.5 \mathrm{~m}$. 

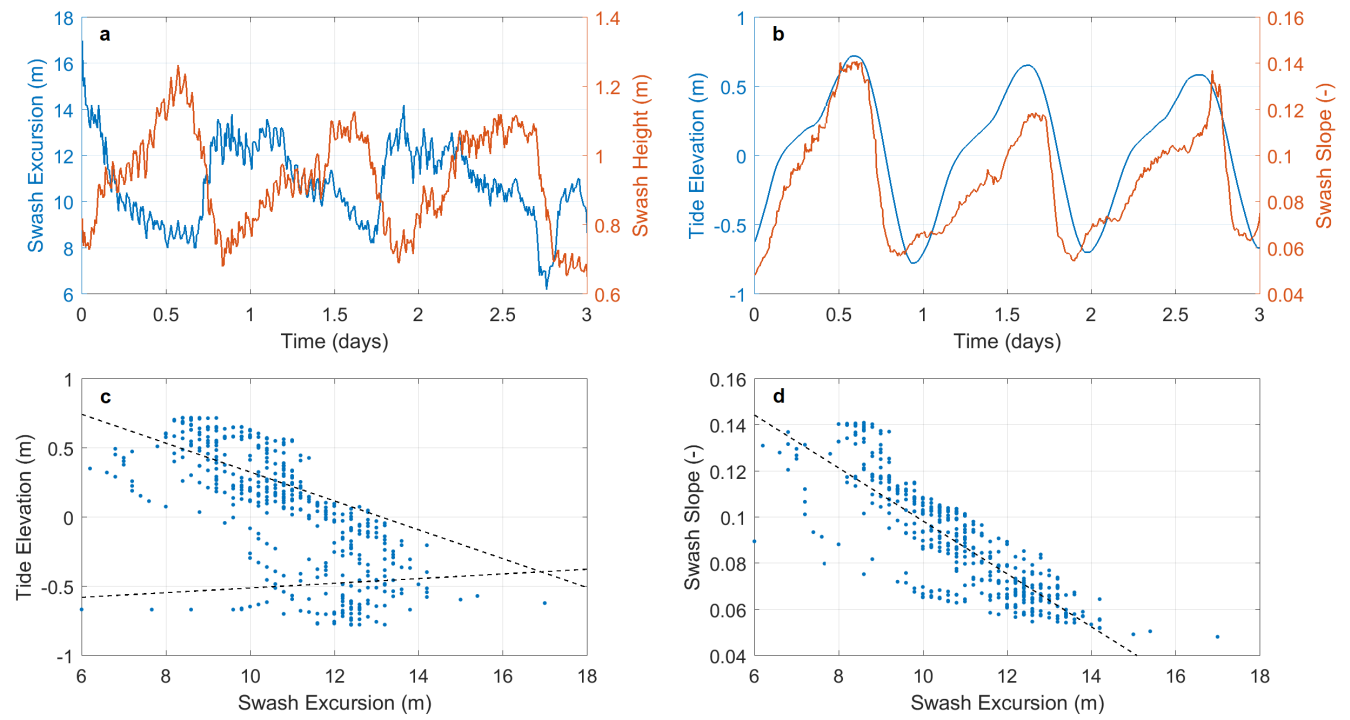

Figure 9: (Top panels) Temporal variation of swash excursion and swash height (a), and tide elevation and swash slope (b). (Bottom panels) Scatter plots of tide elevation (c) and swash slope (d) against swash excursion. Lines of best fit (black, dashed) are shown in (c) for data above and below $-0.1 \mathrm{~m}$ tide elevation, and in (d) for all data.

surface and under layers. Both classes are equally distributed in the sediment bed at the start of the simulation; however as time passes, the surface sediment composition $\left(P_{D_{50}}\right)$ changes. The finer sediment fraction is generally displaced from the swash zone and deposited on the low tide terrace while the coarser sediment fraction armours the swash (Fig. 10c-h). Despite this, there are still times when fine sediment will be pushed back into the surf zone during the rising tide (Fig. 10a); therefore, there is still a mixture of fine and coarse sediment in the surf zone over time. This mixture of fine and coarse sediment creates a pattern surrounding the cusp field with similar length scales as $\widetilde{z b, y}$ (which identifies the cusp horns and troughs); therefore, it is possible investigate their long-shore correlation. This result is shown 

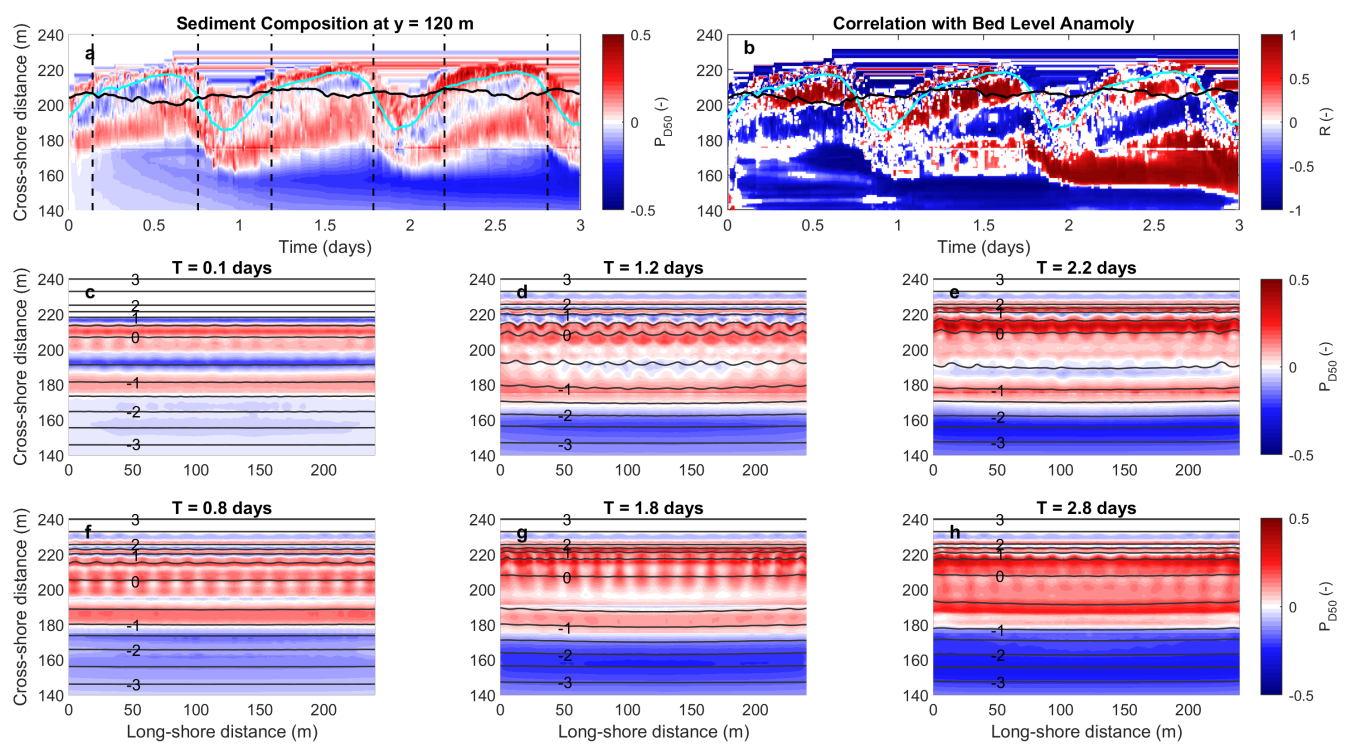

Figure 10: (a-b) Temporal evolution of (a) surface sediment composition $\left(P_{D_{50}}\right)$ along the central cross-shore profile $(y=120 \mathrm{~m})$, and $(\mathrm{b})$ the correlation between $P_{D_{50}}$ and $\widetilde{z_{b, y}}$. Solid black and blue lines show the time-varying movement of the cross-shore position of the shoreline $(\mathrm{z}=0 \mathrm{~m})$ and the tide water level, respectively. (c-h) Spatial variation of $P_{D_{50}}$ at (c-e) mid-tide level on a rising tide and (f-h) mid-tide level on a falling tide. Dashed black lines in (a) indicate the times when (c-h) are shown. Black lines in (c-h) indicate bed level contours drawn at $0.5 \mathrm{~m}$ intervals. The colour scale in (a, c-h) is white (values near 0) for an evenly mixed bed (50\% coarse and 50\% fine sediment). Red colours (positive values up to 1) indicate a greater presence of coarser sediment, and vice versa for blue colours (negative values down to -1). Finally, the color scale in (b) is white (values near 0) when there is no correlation between $P_{D_{50}}$ and $\widetilde{z_{b, y}}$. Red colours indicate there is a positive correlation (coarser sediment located on cusp horn), and vice versa for blue colours (coarser sediment located in cusp trough).

in Fig. 10b, where temporal patterns of strong positive (and negative) correlations can be seen. Positive (negative) correlations shown in red (blue) indicate times when coarser sediment is found on the horn (trough) of the 
cusps. The pattern of correlation fluctuates with tidal elevation but is generally positively correlated around the time-varying water level (i.e. coarser sediment located on the horn). Nonetheless, there are times when the exposed sediment composition pattern shows that coarser sediment is located in the trough of the cusp rather than on the crest (e.g. the upper beach during the second low tide).

\section{Discussion}

\subsection{Evaluation of Length Scales}

\subsubsection{Comparison to Measurements at Nha Trang Beach}

As we have used conditions representative of the situation at Nha Trang Beach as the basis of our simulations, we therefore look to compare simulated values of $L_{y}$ to what was actually measured $(28 \mathrm{~m})$. Hardly any of the cases in Series A come close, with mean $L_{y}$ of $16.5 \mathrm{~m}$. Even case C1, run with measured $H_{s}$ and $T_{m}$ values, underestimates the measured value by almost a third, with a final $L_{y}$ of $19.2 \mathrm{~m}$. However, it should be noted that simulations in Series A and Series C are run with normally incident waves without directional spreading. However, we have seen from Series B that accounting for slight increases in $\sigma$ and $\theta$ would result in larger values of $L_{y}$ (cases B1 and B4) that are more comparable to the measured value $\left(L_{y}>26\right.$ $\mathrm{m})$. Simulated values of $\beta$ in the base case and case $\mathrm{C} 1$ follow similar trends as the measurements, being steepest around high tide and vice versa around low tide. The range of simulated values are also around the same range as the measurements, between 0.04 and 0.12. $S_{x}$ tends to be maximum at low tide in the simulations (where $\beta$ is lowest) while, on the other hand, it is 
maximum around high tide in the measured data (where $\beta$ is highest).

If we consider the average wave conditions (defined by $H_{s}$ and $T_{m}$ ) for case $\mathrm{C} 1$ during the 3 -day simulation period (approximately $1.17 \mathrm{~m}$ and $10 \mathrm{~s}$, respectively), it would fall between the time-constant forcing values of case A6 and A10. Wave conditions peaked during the first tide cycle $(1.4 \mathrm{~m}$ and $11.5 \mathrm{~s}$, similar to case A11), and were lowest during the last tidal cycle (1.0 $\mathrm{m}$ and $8.5 \mathrm{~s}$, similar to case A5). The cusps produced at the end of the simulation in $\mathrm{C} 1$ are of similar magnitude as case A6, A10 and A11 (midto high-end of the wave conditions). After being formed during the first tide cycle, $L_{y}$ did not adapt to the smaller dimensions expected during the lower energy conditions (shown for case A5). Instead, $L_{y}$ remains fairly constant as energy levels fall, as also observed in the field. Thus, the sequencing of wave conditions can affect resultant cusp spacing, as commonly noted in the field where pre-existing cusp formations may persist for some time before newer cusp fields are able to develop, largely depending on how quickly and to what degree actual wave conditions change (van Gaalen et al., 2011).

Finally, we note that $L_{y}$ does not vary significantly between high and mid-tide in our simulations or from the observations at Nha Trang Beach, perhaps due to the micro-tidal environment. Nolan et al. (1999) were able to show a dependence of $L_{y}$ on elevation above MSL; however, their study site was located in a meso-tidal environment (2.6 m range) exposed to more energetic wave conditions.

\subsubsection{Comparison to Empirical and Theoretical Formulae}

Empirical equations for predicting $L_{y}$ have been developed based on field observations. Once such by Sunamura (2004) uses the sediment diameter 
$\left(D_{50}\right)$, wave period, wave height, and gravitational acceleration $(g)$ as dependent variables, given as:

$$
L_{y, \text { Sun }}=A \exp \left(-0.23 D_{50}^{0.55}\right) T \sqrt{g H}
$$

where $A$ is a scaling factor ranging from $\sim 0.65$ for laboratory cases to $\sim 1.35$ for field cases. Expected values of $L_{y}$ may also be calculated based on both the self-organisation and edge wave generation theories, shown, respectively, in Eq. 6 and Eq. 7 following as:

$$
\begin{gathered}
L_{y, S O}=f S_{x} \\
L_{y, E W}=\frac{g T_{i}^{2}}{m \pi} \sin \beta
\end{gathered}
$$

where $f$ is a factor generally taken to be 1.63 (but which may range between 1 and 3$) ; S_{x}$ is the swash excursion; $m$ is a factor equal to 1 and 2 for subharmonic $\left(L_{y, S u b}\right)$ and synchronous $\left(L_{y, S y n}\right)$ edge waves, respectively; $\beta$ is the beach slope; and $T_{i}$ is the incoming wave period (Coco et al., 1999). Results are shown in Table 4 for final values of $S_{x}$ (extracted from the model output around $\mathrm{T}=2.83$ days), from which final values of $\beta$ and $f$ are computed. Values of $L_{y, S u b}, L_{y, S y n}, L_{y, S O}$, and $L_{y, S u n}$ are also shown for comparison with Series A. It should be noted that some scatter is expected in our data as we are unable to control exactly where along a cusp (between the horn and trough) $S_{x}$ and $\beta$ are extracted, as the exact position of cusps at the central cross-shore profile varies during the course of the simulation for each case. 
When using Eq. 5 to compute $L_{y, \text { Sun }}$ in Table 4 , we computed and used the value of $A$ that minimised the root-mean-square error (the best-fit value) between $L_{y, \text { Sun }}$ and $L_{y}$, which was equal to 0.6 - very close to the value of 0.65 reported in Sunamura (2004). Values of $L_{y, \text { Sun }}$ are not much different to the simulation results of Series A, with raw error around $14 \%$ on average. Applying Eq. 5 to the average measured wave conditions (1 m, 9 s) and using the field value of $A=1.35$, we obtain a predicted value of $L_{y, \text { Sun }}$ of $32 \mathrm{~m}$, a slight over-prediction. Thus, Eq. 5 predicts $L_{y}$ reasonably well for both Series A (laboratory-type cases which have no directional spreading and normally incident waves) and for the actual field case at Nha Trang Beach. For Series B, where $\theta$ and $\sigma$ are increased, using $A=0.6$ largely underestimates $L_{y}$. The estimate is improved when using $A=1.35$, with a best-fit value of 1.7. Sunamura (2004) noted the large difference between $A$ obtained for laboratory and field data, attributing the larger field value to irregular wave forcing in the field. However, it should also be noted that slight increases in $\theta$ and $\sigma$ in Series B also enhanced $L_{y}$, which may also help to account for the larger $A$ values of field cases, since there is at least some degree of directional spreading expected.

Table 4 shows that simulated $\beta$ and $f$ generally increase with $H_{s}$ and $T_{m}$. With regard to $f$, the simulation results ranges from 1.16 to 2.47 , which fits within the range of expected $f$ values (1 to 3 ). The best-fit value of $f$ is found to be 1.63 - equal to that reported in Coco et al. (1999). As $f$ varies according to specific forcing conditions, values of $L_{y, S O}$ overestimate $L_{y}$ at low $H_{s}$ and $T_{m}$ values (such as case A1 or A4) and vice versa at high $H_{s}$ and $T_{m}$ values (such as case A11 or A14). Almar et al. (2008) and Vousdoukas 
(2012) have reported observed mean $f$ values of 1.69 and 3.47, respectively, under average wave conditions of $\left[H_{s}, T_{m}\right]=[1.5 \mathrm{~m}, 10 \mathrm{~s}]$ at Tairua Beach (former), and $=[1 \mathrm{~m}, 8 \mathrm{~s}]$ at Faro Beach (latter). While the observed $f$-value of Almar et al. (2008) is not much different with our findings from Series A ( $\theta$ is reported to be almost always shore normal), that of Vousdoukas (2012) is much larger than expected. For the latter, it is important to note that there were large variations of measured $\theta$ values, up to $40^{\circ}$. This may help to explain why the observed $L_{y}$ (on average $50 \mathrm{~m}$ ) is quite large in comparison to the measured $S_{x}$. As seen from our simulations, for $\theta \geq 10^{\circ}$ (cases B5 and B6) we obtain mean $f$ values of 5.8 and $L_{y}$ of $45 \mathrm{~m}$ - comparable to Vousdoukas (2012).

Regarding the synchronous edge wave theory, $L_{y, \text { Syn }}$ significantly underestimates $L_{y}$ for cases with lower $H_{s}$ and $T_{m}$ values (for cases A1-A5, around $48 \%$ lower) and vice versa at high $H_{s}$ and $T_{m}$ values (for cases A10-A14, around $12 \%$ higher). Alternatively, for sub-harmonic edge waves, $L_{y, \text { Sub }}$ slightly overestimates $L_{y}$ for cases with lower $H_{s}$ and $T_{m}$ values (for cases A1-A5, around 5\% lower) but severely overestimates $L_{y}$ at high $H_{s}$ and $T_{m}$ values (for cases A10-A14, around $125 \%$ higher). Similar findings are shown in Dodd et al. (2008), though only $T_{m}$ was varied in their simulations. Therefore, $L_{y, \text { Sub }}$ predictions would appear to be suited to low wave energy conditions and those for $L_{y, S y n}$ to higher energy conditions; but neither are very good predictors across the board when compared to $L_{y}$. Guza and Inman (1975) note that sub-harmonic edge waves are more easily generated than synchronous edge waves, and that both are not generally found under energetic wave conditions, where the high turbulence of plunging breakers 
disrupts their excitation. The generation of certain types of edge waves in itself is also highly dependent on, inter alia, beach topography, frequency spread of incident waves, and dissipation by waves and currents. Therefore it is not clear which edge wave mode is best suited for comparison to $L_{y}$. Indeed in the literature, comparisons between measured data and theoretical edge wave predictions vary widely from being strongly to weakly correlated (Kaneko, 1985; Rasch et al., 1993; Almar et al., 2008) and even distinguishing between different modes of edge waves may be difficult in reality (Holland and Holman, 1996). Nevertheless, it may be possible to identify edge waves using XBeach (whether synchronous or sub-harmonic) from seaward radiating wave reflection patterns. As shown in Fig. 7, a pattern of alternating perturbations in $\left\langle\widetilde{H_{s, y}}\right\rangle$ is seen during the initial development of cusps, obviously caused by the interaction between incoming and reflected waves (similar to Almar et al. (2018)). However, our model output is not saved at a high enough frequency to separate incoming from reflected waves, and we are thus unable to definitively quantify the presence of edge waves. Nonetheless, this may be looked at in greater detail in future work that is more focused on mechanisms surrounding cusp initiation.

\subsection{Evaluation of development, circulation and sediment patterns}

We have shown in our simulations that increased $T_{m}$ generally results in increased $L_{y}$. Longer intervals between swash events for higher period waves would tend to reduce bore (swash-swash) interactions occurring on the beachface, allowing stronger return flow during the backwash capable of sculpting wider cusps. Dodd et al. (2008) obtained similar results, and showed that the swash period may resonate with the incoming wave period to enhance 


\begin{tabular}{|c|c|c|c|c|c|c|c|c|}
\hline $\begin{array}{l}\text { Run } \\
\text { ID }\end{array}$ & $\begin{array}{l}S_{x} \\
(\mathbf{m})\end{array}$ & $\begin{array}{l}\beta \\
(-)\end{array}$ & $\begin{array}{l}f \\
(-)\end{array}$ & $\begin{array}{l}L_{y} \\
(\mathbf{m})\end{array}$ & $\begin{array}{l}L_{y, S u b} \\
(\mathbf{m})\end{array}$ & $\begin{array}{l}L_{y, \text { Syn }} \\
(\mathbf{m})\end{array}$ & $\begin{array}{l}L_{y, S O} \\
(\mathbf{m})\end{array}$ & $\begin{array}{l}L_{y, \text { Sun }} \\
(\mathbf{m})\end{array}$ \\
\hline A1 & 9.8 & 0.044 & 1.16 & 11.4 & 10.2 & 5.1 & 16.0 & 9.8 \\
\hline $\mathrm{A} 2$ & 9.3 & 0.052 & 1.85 & 17.3 & 17.1 & 8.5 & 15.2 & 11.7 \\
\hline A 3 & 8.5 & 0.055 & 2.29 & 19.6 & 24.0 & 12.0 & 13.9 & 13.4 \\
\hline $\mathrm{A} 4$ & 10.0 & 0.055 & 1.23 & 12.3 & 12.7 & 6.3 & 16.3 & 11.7 \\
\hline A 5 & 12.0 & 0.048 & 1.18 & 14.2 & 15.9 & 8.0 & 19.6 & 14.0 \\
\hline $\mathrm{A} 6$ & 8.3 & 0.071 & 2.19 & 18.2 & 30.7 & 15.4 & 13.6 & 16.1 \\
\hline $\mathrm{A} 7$ & 8.2 & 0.078 & 2.47 & 20.3 & 44.1 & 22.1 & 13.4 & 18.3 \\
\hline A 8 & 11.4 & 0.056 & 1.17 & 13.3 & 13.0 & 6.5 & 18.5 & 13.4 \\
\hline A9 & 9.6 & 0.072 & 1.56 & 15.0 & 23.8 & 11.9 & 15.7 & 15.9 \\
\hline A10 & 9.5 & 0.075 & 1.80 & 17.0 & 32.5 & 16.2 & 15.4 & 18.3 \\
\hline A11 & 8.5 & 0.094 & 2.17 & 18.5 & 53.2 & 26.6 & 13.9 & 20.9 \\
\hline A12 & 9.9 & 0.081 & 1.36 & 13.4 & 26.8 & 13.4 & 16.1 & 18.2 \\
\hline A13 & 12.2 & 0.083 & 1.77 & 21.6 & 36.1 & 18.0 & 19.8 & 20.9 \\
\hline A14 & 11.1 & 0.092 & 1.69 & 18.7 & 51.9 & 25.9 & 18.0 & 23.9 \\
\hline B1 & 12.5 & 0.066 & 2.08 & 26.1 & - & - & - & - \\
\hline B2 & 11.9 & 0.064 & 5.66 & 67.4 & - & - & - & - \\
\hline B3 & 13.9 & 0.061 & 4.12 & 57.3 & - & - & - & - \\
\hline B4 & 8.1 & 0.115 & 3.33 & 26.9 & - & - & - & - \\
\hline B5 & 7.3 & 0.098 & 6.79 & 49.5 & - & - & - & - \\
\hline B6 & 8.4 & 0.096 & 4.80 & 40.2 & - & - & - & - \\
\hline $\mathrm{C} 1$ & 13.9 & 0.059 & 1.39 & 19.2 & - & - & - & - \\
\hline $\mathrm{C} 2$ & 13.5 & 0.060 & 1.48 & 20.0 & - & - & - & - \\
\hline C3 & 13.2 & 0.063 & 2.10 & 27.7 & - & - & - & - \\
\hline $\mathrm{C} 4$ & 14.9 & 0.083 & 1.29 & 19.3 & - & - & - & - \\
\hline
\end{tabular}

Table 4: Simulation results of $S_{x}, \beta, f$ and $L_{y}$ for Series A, B and C, with Series A compared with expectations from the edge wave (sub-harmonic and synchronous) and self-organisation theories, and Sunamura (2004) $\left(L_{y, S u b}, L_{y, S y n}, L_{y, S O}\right.$ and $L_{y, S u n}$, respectively). 
backwash. Our simulations also showed that increased $H_{s}$ leads to larger $L_{x}$ and $L_{z}$, most likely caused by greater turbulence in the swash capable of reworking sediment into deeper and wider cusp features. All simulations with developed cusps featured horn-divergent flow patterns, as is commonly observed in the field (Masselink and Pattiaratchi, 1998b; Holland, 1998) and predicted by other numerical studies (Dodd et al., 2008).

Cusp dimensions are enhanced when $\sigma$ (under normally incident waves) or $\theta$ are low $\left(\sim 5^{\circ}\right)$. Larger values are shown to cause increased turbulence in the swash, which acts to inhibit cusp growth. Increased turbulence may be due to the effect of greater swash-swash interactions $(\sigma>0)$ or asymmetric swash flow $\theta>0$ ). Obliquely incident waves of $20^{\circ}$ have been observed in the field to flatten cuspate features (Masselink and Pattiaratchi, 1998a). Holland (1998) also noted that cusps are rarely observed, and tend to be destroyed, for angles of incidence greater than $12^{\circ}$. Holland (1998) suggests that as $\theta$ increases, long-shore currents increasingly disrupt the cross-shore flow structure needed to form and maintain cusps. In our simulations where $\theta$ is varied, only case B4 resulted in a prominent cusp shape. While B5 and B6 do produce shoreline undulations, they have high aspect ratios which diminish their prominence.

In terms of the sediment sorting pattern around cusps, by looking at the correlation between $P_{D_{50}}$ and $\widetilde{z_{b, y}}$ in Fig. 10b, we showed that sediment is generally coarser on the horns than in the trough of the cusps. This is true for most field observations, such as Antia (1987) and Sallenger (1979) who also explains that, as swash flow is more powerful than backwash and as flow is generally horn divergent, fine sediment is removed from the horn (leaving 
coarser sediment behind) and deposited in the trough.

The effect of varying sediment size, by decreasing $D_{50}$, we obtain slight increases in $L_{y}$, as noted in Sunamura (2004). However, it comes at the expense of increasing the erodability of the beach (i.e. more dissipative), making cusps less prominent. In fact, case C3 the final profile is generally devoid of any shoreline features. The present results therefore show cusps tend to form under accretive and mildly erosive conditions on coarse grained intermediate beaches, consistent with field observations (Holland, 1998; van Gaalen et al., 2011). Antia (1987) notes that while cusps may form on typically dissipative beaches, they only appear during low energy events which may permit a temporary reflective beach state to form.

\subsection{XBeach Sediment Transport Module}

The simulations have been done using the non-hydrostatic wave solver in XBeach while enabling sediment transport. This is quite experimental, as the sediment transport equations only account for transport due to flow and wave-averaged orbital motions and therefore do not resolve intra-wave transport mechanisms. Furthermore, the use of the parameter settings in Table 1 with the Kingsday version of XBeach allows bedload transport to be only onshore-directed, which is an unusual result that is repaired in subsequent model releases. Nonetheless, an appropriate balance between onshore and offshore transport fluxes are obtained for our simulations despite these shortcomings. Further development of XBeach is therefore necessary to better and more realistically account for intra-wave and swash sediment transport processes. One suggestion to the model developers may be, for example, introducing acceleration dependent onshore fluxes as can be determined 
from gradients in the surface elevation computed by the non-hydrostatic wave solver.

\section{Conclusion}

A number of exploratory morphodynamic simulations were carried out to study beach cusp formation, inspired by observations at Nha Trang Beach, Vietnam. The simulations used time-constant and time-varying (measured) wave forcing conditions. In the former, the length scale of cusp formations were analysed as a function of the significant wave height, mean wave period, directional spreading and angle of incidence $\left(H_{s}, T_{m}, \sigma\right.$ and $\theta$, respectively). The resulting cusp length scales varied according to well-established norms - $H_{s}$ modulates cusp height and cross-shore depth, while $T_{m}, \sigma$ and $\theta$ affect long-shore length scales. Cusps appear to be most prominent for longer period waves $(>10 \mathrm{~s})$ with moderate wave heights $(>1.3 \mathrm{~m})$. Slightly increased $\sigma$ and $\theta$ enhances long-shore length scales, but tends to make cusps less prominent at values $>10^{\circ}$. The model was able to produce asymmetric cusp patterns for obliquely incident waves.

Time-varying (measured) wave conditions with the native sediment size produced cusps with smaller length scales to those measured; however, it may be possible to achieve a more comparable spacing by including directional variations. Reducing the median sediment diameter, $D_{50}$, in other simulations with time-varying wave conditions allowed more dissipative beach profiles to form, resulting in net erosion of the beachface (as opposed to accretion in the previous simulations). Cusps were able to form under mildly erosive conditions (using $D_{50}=0.3 \mathrm{~mm}$ ), though not as prominent as when 
formed under accretive conditions. Cusps were not able to form under more intense erosion (using $D_{50}=0.2 \mathrm{~mm}$ ). This finding is in keeping with the many observations of cusps being found on coarse sand beaches rather than fine sand beaches. The model also showed a general tendency for coarse sediment to be located on the crest of cusps near the water line, though the inverse pattern was seen at other elevations on the beach face.

Given that the model is able to reasonably simulate the formation of cusps of varying length scales and prominence, the process of cusp initiation can be studied in more detail in future work. Initial results show there is a significant correlation between the long-shore wave height and bed level anomalies, which may be produced by wave reflection patterns as suggested in Almar et al. (2018). It is currently unknown to what extent edge waves play a role in cusp formation; however, this study provides a basis for more rigorous investigation of this enigmatic topic using the XBeach model.

\section{Acknowledgements}

This research has received support from French grants through ANR (COASTVAR: ANR-14-ASTR-0019) and CG29 subvention. The authors would like to thank all the participants present in the Nha Trang field experiment for the help provided. CD acknowledges the Conseil Départemental du Finistère, LabexMer (ANR-10-LABX-19), and the Marie Curie Prestige Fellowship Program for providing financial support for his postdoctoral research at UBO. CD also acknowledges Jaap Nienhuis and NSF Award No. 1810855 for support during his postdoctoral stay at Florida State University. The authors thank Giovanni Coco and two other anonymous reviewers for 
their detailed comments and feedback, which greatly helped to improve the quality of the manuscript.

\section{Author Contributions}

FF, RA and LPA designed and carried out the field campaign and in-situ data collection at Nha Trang beach. MJ produced the orthophoto beach DEM from the drone measurements. CD designed and performed the model simulations, post-processed measured data, analysed the model results and produced the figures. The manuscript was written and revised by CD, with comments from other co-authors.

\section{Conflicts of Interest}

The authors declare no conflict of interest.

\section{References}

Almar, R., Coco, G., Bryan, K., Huntley, D., Short, A., Senechal, N., 2008. Video observations of beach cusp morphodynamics. Marine Geology 254, $216-223$.

Almar, R., Lerma, A.N., Castelle, B., Scott, T., 2018. On the influence of reflection over a rhythmic swash zone on surf zone dynamics. Ocean Dynamics 68, 899-909.

Almeida, L.P., Almar, R., Blenkinsopp, C., Senechal, N., Bergsma, E., Floc'h, F., Caulet, C., Biausque, M., Marchesiello, P., Grandjean, P., Ammann, J., Benshila, R., Thuan, D.H., Gomes da Silva, P., Viet, N.T., 
2020. Lidar observations of the swash zone of a low-tide terraced tropical beach under variable wave conditions: The nha trang (vietnam) coastvar experiment. Journal of Marine Science and Engineering 8, 302. doi:doi:10.3390/jmse8050302.

Antia, E., 1987. Preliminary field observations on beach cusp formation and characteristics on tidally and morphodynamically distinct beaches on the nigerian coast. Marine Geology 78, 23-33.

Bakhtyar, R., Barry, D., Jeng, D., Li, L., Yeganeh-Bakhtiary, A., 2009. Modeling sediment transport in the swash zone: A review. Ocean Engineering $36,767-783$.

de Bakker, A., Tissier, M., Ruessink, B., 2014. Shoreline dissipation of infragravity waves. Continental Shelf Research 72, 73-82.

Coco, G., Burnet, T., Werner, B., Elgar, S., 2003. Test of self-organization in beach cusp formation. J. Geophys. Res 108, 3101.

Coco, G., Huntley, D., O'Hare, T., 2000. Investigation of a self-organization model for beach cusp formation and development. Journal of Coastal Research 105, 21991-22002.

Coco, G., Huntley, D., O'Hare, T., 2001. Regularity and randomness in the formation of beach cusps. Marine Geology 178, 1-9.

Coco, G., O'Hare, T., Huntley, D., 1999. Beach cusps: a comparison of data and theories for their formation. Journal of Coastal Research 15, 741-749. 
Daly, C., Floc'h, F., Almeida, L.P., Almar, R., 2017. Modelling accretion at nha trang beach, vietnam. Proceedings of the International Conference on Coastal Dynamics, Helsingor, Denmark, 1886-1896.

Dodd, N., Stoker, A., Calvete, D., Sriariyawat, A., 2008. On beach cusp formation. Journal of Fluid Mechanics 597, 145-169.

Elgar, S., Gallagher, E., Guza, R., 2001. Nearshore sandbar migration. Journal of Geophysical Research 106, 11623-11627.

van Gaalen, J., Kruse, S., Coco, G., Collins, L., Doering, T., 2011. Observations of beach cusp evolution at melbourne beach, florida, usa. Geomorphology 129.

Garnier, R., Ortega-Sanchez, M., Losada, M., Falques, A., Dodd, N., 2010. Beach cusps and inner surf zone processes: growth or destruction? a case study of trafalgar beach (cadiz, spain). Scientia Marina 74, 539-553. doi:10.3989/scimar.2010.74n3539.

Guza, R., Inman, D., 1975. Edge waves and beach cusps. Journal of Geophysical Research: Oceans and Atmosphere 80, 2997-3012.

Holland, K., 1998. Beach cusp formation and spacings at duck, usa. Continental Shelf Research 18, 1081-1098.

Holland, K., Holman, R., 1996. Field observations of beach cusps and swash motions. Marine Geology 134, 77-93.

Inman, D., Guza, R., 1982. The origin of swash cusps on beaches. Marine Geology 49, 133-148. 
Kaneko, A., 1985. Formation of beach cusps in a wave tank. Coastal Engineering $9,81-98$.

Lashley, C.H., Roelvink, D., van Dongeren, A., Buckley, M.L., Lowe, R.J., 2018. Nonhydrostatic and surfbeat model predictions of extreme wave run-up in fringing reef environments. Coastal Engineering 137, 11-27.

Masselink, G., Hegge, B.J., Pattiaratchi, C.B., 1997. Beach cusp morphodynamics. Earth Surface Processes and Landforms 22, 1139-1155.

Masselink, G., Pattiaratchi, C., 1998a. Morphodynamic impact of sea breeze activity on a beach with beach cusp morphology. Journal of Coastal Research 14, 393-406.

Masselink, G., Pattiaratchi, C., 1998b. Morphological evolution of beach cusps and associated swash circulation patterns. Marine Geology 146, 93-113.

McCall, R., Masselink, G., Roelvink, J., Russell, P., Davidson, M., Poate, T., 2012. Modeling overwash and infiltration on gravel barriers. Proceedings of the 33rd International Conference on Coastal Engineering, Santander, Spain .

Nolan, T., Kirka, R., Shulmeister, J., 1999. Beach cusp morphology on sand and mixed sand and gravel beaches, south island, new zealand. Marine Geology 157, 185-198.

O’Dea, A., Brodie, K., 2019. Spectral analysis of beach cusp evolution using 3d lidar scans. Proceedings of the 9th International Conference on Coastal Sediments, Tampa/St. Petersburg, Florida, World Scientific , 657-673. 
Rasch, M., Nielsen, J., Nielsen, N., 1993. Variations of spacings between beach cusps discussed in relation to edge wave theory. Geografisk Tidsskrift - Danish Journal of Geography 93, 49-55.

van Rhee, C., 2010. Sediment entrainment at high flow velocity. Journal of Hydraulic Engineering 136, 572-582.

van Rijn, L., 2007a. Unified view of sediment transport by currents and waves. i: initiation of motion, bed roughness, and bed-load transport. Journal of Hydraulic Engineering 133, 649-667.

van Rijn, L., 2007b. Unified view of sediment transport by currents and waves. ii: suspended transport. Journal of Hydraulic Engineering 133, 668-689.

Roelvink, D., van Dongeren, A., McCall, R., Hoonhout, B., van Rooijen, A., van Geer, P., de Vet, L., Nederhoff, K., Quataert, E., 2015. Xbeach technical reference: Kingsday release model description and reference guide to functionalities. Deltares, UNESCO-IHE Institute of Water Education and Delft University of Technology .

Roelvink, D., van Dongeren, A., McCall, R., Hoonhout, B., van Rooijen, A., van Geer, P., de Vet, L., Nederhoff, K., Quataert, E., 2018. Improving predictions of swash dynamics in xbeach: The role of groupiness and incident-band runup. Coastal Engineering 134, 103-123. doi:doi.org/10.1016/j.coastaleng.2017.07.004.

Roelvink, D., Reniers, A., van Dongeren, A., van Thiel de Vries, J., McCall, 
R., Lescinski, J., 2009. Modelling storm impacts on beaches, dunes and barrier islands. Coastal Engineering 56, 1133-1152.

Ruessink, B., Ramaekers, G., van Rijn, L., 2012. On the parameterization of the free-stream non-linear wave orbital motion in nearshore morphodynamic models. Coastal Engineering 65, 56-63.

Ruffini, G., Briganti, R., Alsina, J.M., Brocchini, M., $2020 . \quad \mathrm{Nu}-$ merical modeling of flow and bed evolution of bichromatic wave groups on an intermediate beach using nonhydrostatic xbeach. Journal of Waterway, Port, Coastal, and Ocean Engineering 146. doi:doi.org/10.1061/(ASCE)WW.1943-5460.0000530.

Sallenger, A., 1979. Beach cusp formation. Marine Geology 29, 23-37.

Soulsby, R., 1997. Dynamics of marine sands: a manual for practical applications. Thomas Telford Publications, London.

Sunamura, T., 2004. A predictive relationship for the spacing of beach cusps in nature. Coastal Engineering 51, 697-711.

Talmon, A., van Mierlo, M., Struiksma, N., 1995. Laboratory measurements of the direction of sediment transport on transverse alluvial-bed slopes. Journal of Hydraulic Research 33, 495-517.

Vousdoukas, M., 2012. Erosion/accretion patterns and multiple beach cusp systems on a meso-tidal steeply-sloping beach. Geomorphology 141-142, $34-46$. 
782 Walstra, D., van Rijn, L., van Ormondt, M., Briere, C., Talmon, A.M., 2007. The effects of bed slope and wave skewness on sediment transport and morphology. Proceedings of the Sixth International Symposium on Coastal Sediments, ASCE , 137-150.

van der Werf, J., Ribberink, J., Kranenburg, W., Neessen, K., Boers, M., 2017. Contributions to the wave-mean momentum balance in the surf zone. Coastal Engineering 121, 212-220.

Werner, B., Fink, T., 1993. Beach cusps as self-organized patterns. Science 260, 968-971.

Zijlema, M., Stelling, G.S., Smit, P.B., 2011. Swash: An operational public domain code for simulating wave fields and rapidly varied flows in coastal waters. Coastal Engineering 58, 992-1012. 